\title{
A Study of Deep Neural Network Controller-Based Power Quality Improvement of Hybrid PV/Wind Systems by Using Smart Inverter
}

\author{
Adel Ab-BelKhair $(\mathbb{D}$, Javad Rahebi $(\mathbb{D}$, and Abdulbaset Abdulhamed Mohamed Nureddin \\ Department of Electrical and Computer Engineering, Altinbas University, Turkey \\ Correspondence should be addressed to Javad Rahebi; cevat.rahebi@altinbas.edu.tr
}

Received 16 April 2020; Revised 22 October 2020; Accepted 16 November 2020; Published 17 December 2020

Academic Editor: Alberto Álvarez-Gallegos

Copyright ( $) 2020$ Adel Ab-BelKhair et al. This is an open access article distributed under the Creative Commons Attribution License, which permits unrestricted use, distribution, and reproduction in any medium, provided the original work is properly cited.

\begin{abstract}
Presently, climate change and global warming are the most uncontrolled global challenges due to the extensive fossil fuel usage for power generation and transportation. Nowadays, most of the developed countries are concentrating on developing alternative resources; consequently, they did huge investments in research and development. In general, alternative energy resources including hydropower, solar power, and wind energy are not harmful to nature. Today, solar power and wind power are very popular alternative energy sources due to their enormous availability in nature. In this paper, the photovoltaic cell and wind energy systems are investigated under various weather conditions. Based on the findings, we developed an advanced intelligent controller system that tracks the maximum power point. The MPPT controller is a must for the renewable energy sources due to unpredictable weather conditions. The main objective of this paper is to propose a new algorithm that is based on deep neural network (DNN) and maximum power point tracking (MPPT), which was simulated in a MATLAB environment for photovoltaic (PV) and wind-based power generation systems. The development of an advanced DNN controller that improves the power quality and reduces THD value for the microgrid integration of hybrid PV/wind energy system was performed. The MATLAB simulation tool has been used to develop the proposed system and tested its performance in different operating situations. Finally, we analyzed the simulation results applying the IEEE 1547 standard.
\end{abstract}

\section{Introduction}

During the last decade, global warming emerged as a major problem, and its consequences are very intimidating for life on earth. Unpredictable fuel prices and environmental consequences of extensive fuel consumption resulted in attracting the attention of experts to renewable energy (RE) or alternative energy resources. Electric power generation by photovoltaic (PV) and wind power (WP) has played a vital role due to their easy availability and harmless nature $[1,2]$. The RE sources can be integrated with the main electric power grid, which resulted in the emergence of microgrid (MG) and smart grid. Concepts such as hi-tech active transmission and distributive power network, flexible loads, advanced controller, and self-healing technologies are parts of MGs [3-5]. The use of fast-growing RES is enabled with the aid of the use of increased WT and PV reproductive technologies with the main goal of reducing the price of the program. In addition, it might also be argued that wind turbine and solar photovoltaic technology structures are the most extensively adopted and hooked up technologies. As mentioned in [1], electrical energy from RES such as WT and PV will quickly be decreased at lower costs than electricity. Depending on the size, properties and characteristics of WT and PV technological knowhow producers can have a considerable have an effect on strength effectivity in phrases of monetary symptoms such as electrical energy fees in thermal power plants, electricity first rate indicators and electricity loss. 
Hybrid renewable energy technologies are becoming standard technologies for generating electricity because they use several alternative energy sources at the same time. Presently, both wind and solar sources are considered as promising RE sources; specifically, solar energy is considered as more significant because it offers considerable cost reduction [6-8]. The aforementioned hybrid system may have a few drawbacks like integration issues, and besides, its stability may become a challenge, as renewable sources are mostly irregular, unmanageable, stochastic, and highly variable. Some potentially challenging situations can be load discrepancy, voltage variability, poor load following, poor power quality, frequency deviation, and reliability issues [9-11]. High power flow (OPF) ability is the steady monetary overall performance of the power system, which is carried out with the suitable flexibility of the control system. In mathematical formulation, this is a large, nonlinear, nonlinear, static problem, with a complicated linear transformation problem. Multiple WT integration and the tuning of the PV system to the power system will increase the complexity of the OPF trouble due to its transient energy characteristics. A typical framework for defining and resolving the OPF that appears at WT and PV technology has to consist of the following: (i) the importance and context of the issue; (ii) estimating the WT and PV power output due to the dependable traits of wind speed and solar radiation; (iii) choosing goal functions; (iv) outlining technical issues, adaptive control, and dependable diversity; and (v) how to resolve the OPF problem. Recently, a number of researchers have addressed the OPF trouble that focuses on some of the above functions [12-14]. The latest and innovative ideas and technologies are needed to increase the RE sources' penetration in the power grid that helps alleviate these problems.

Another major research challenge is optimization of the hybrid power system in the smart grid framework, in conjunction with the model predictive control (MPC) design. It creates a strategy that can maximise the use of renewable energy, e.g., photovoltaic, the wind turbine with battery storage and minimize the utilization of the utility grid for electricity usage in the industry. The different contexts of using renewable energy resources (RERs) and grid-connected applications are given in [15-18]. It develops the concept of PV energy storage integration in commercial building applications. The microgrid grid environment in conjunction with their technologies into the applications of a microgrid with energy coordination is aimed at creating power flow stability between the generation and consumption of the electricity. The literature surveys on the global energy scenario and renewable energy integration, which mainly involves solar photovoltaic (PV) and battery energy storage systems (BESS). The model predictive regulator plays the major role for controlling the power flow in tie lines and frequency deviations in the microgrid, which will lead to power balance between the total active power generated and active power demand of the system.

This paper presents a novel deep neural network algorithm for solving such problems in power systems with integrated PV and wind generators, which is represented in Figure 1. In this context, the main contributions include the following:
(1) Designing and modeling an MPPT controller for a $\mathrm{PV}$-wind energy system applying DNN and analyzing its performance under various weather conditions

(2) Designing and developing a wind energy system and PV for modeling a smart inverter for integrating a microgrid with the hybrid system

(3) Designing a DNN-based voltage source controller for synchrony between microgrid and the mentioned PV-wind hybrid energy system

(4) The DNN-based smart inverter will help reduce harmonics and improve the power stability and quality

The rest of this paper has been organized in the following format. Section 2 describes the DNN-based MPPT algorithm that is used for PV systems, and this section also analyzes the performance of the algorithm under various weather conditions. Section 3 describes a DNN-based MPPT algorithm (wind energy system) and its performance analysis under various wind speeds and explains the obtained results. The proposed DNN-based microgrid and its integration with PV-wind hybrid power system has been illustrated in Section 4. In Section 5, the DNN-based smart inverter controller has been modeled, which is followed by its performance evaluation. We have presented the simulation results in Section 6 while the conclusions have been listed after Section 6 .

\section{Deep Neural Network-Based MPPT for PV}

The MPPT algorithm is significant for maximizing the power generation from renewable energy sources under various weather conditions. Over the last decade, many researchers focused on developing a new MPPT algorithm using various controllers such as $\mathrm{P} \& \mathrm{O}$, incremental conductance, feedback voltage and current, Fuzzy, ANN, PSO ANFIS, and other controllers $[9,19-22]$. In this paper, the deep neural network (DNN) controller has been used to develop an MPPT algorithm for a photovoltaic system. In this DNN learning algorithm, 66000 data items are used to develop the mentioned MPPT algorithm (Figure 2). The simulation model of the proposed MPPT-based PV system was simulated in a MATLAB environment (Figure 3). The proposed simulation model $20 \mathrm{~kW}$ PV array has been used, and a boost converter was used for stepping up the voltage based on the MPPT algorithm. Figure 4(a) presents the flow chart of the DNN controller, and the DNN layer is shown in Figure 4(b). In this layer, there are a couple of input neurons, 1000 hidden-layer neurons, and an output neuron. This DNN layer has been used for training the MPPT network using data that includes input (PV voltage, PV current) and output in the form of a duty cycle of converter.

The DNN controller has been trained using the above system, and its best validation performance has been presented in Figure 5. The proposed DNN controller error (target-output) histogram data is presented in Figure 6. The optimum number of hidden layers and hidden units 


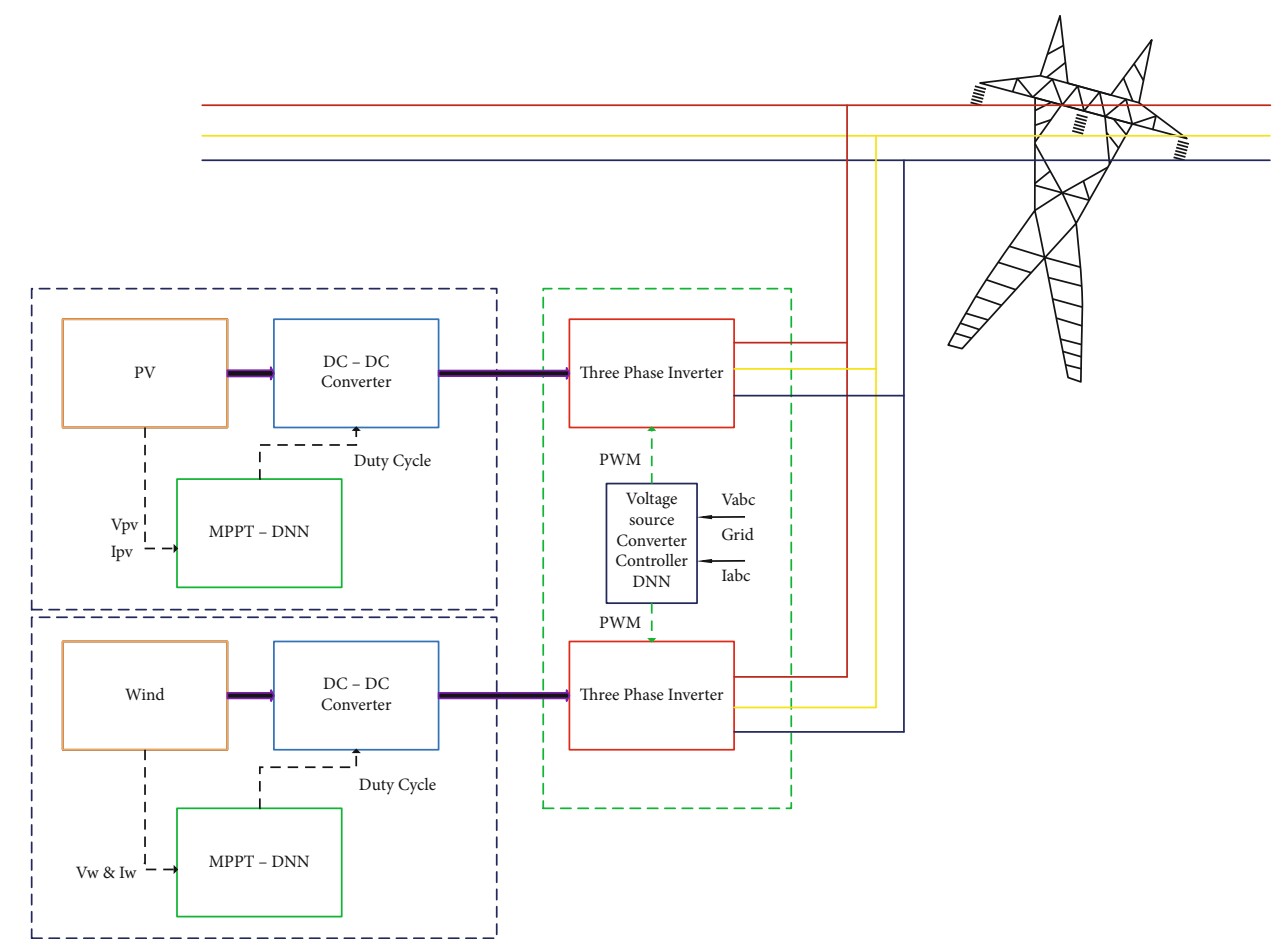

FIGURE 1: Block diagram of the proposed microgrid system and its controller.

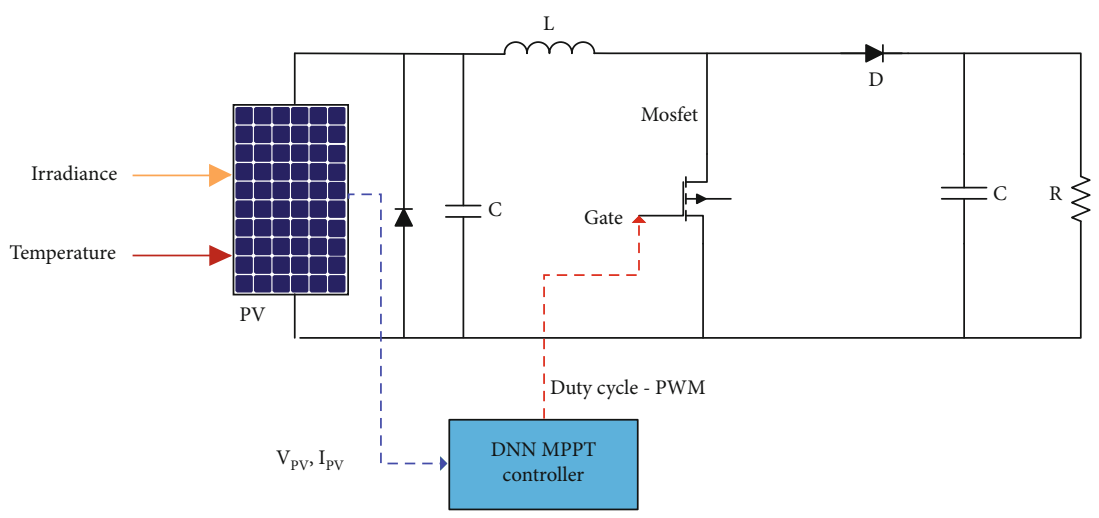

Figure 2: Proposed DNN-based MPPT algorithm.

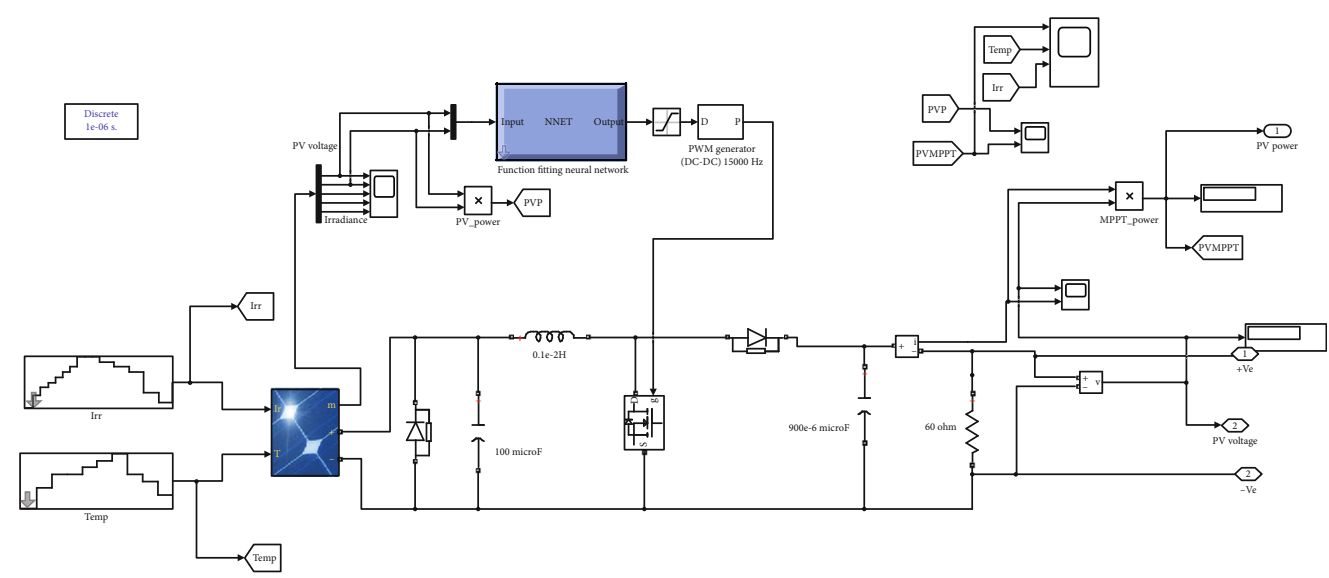

Figure 3: Simulation model of DNN controller-based MPPT algorithm for the PV system. 


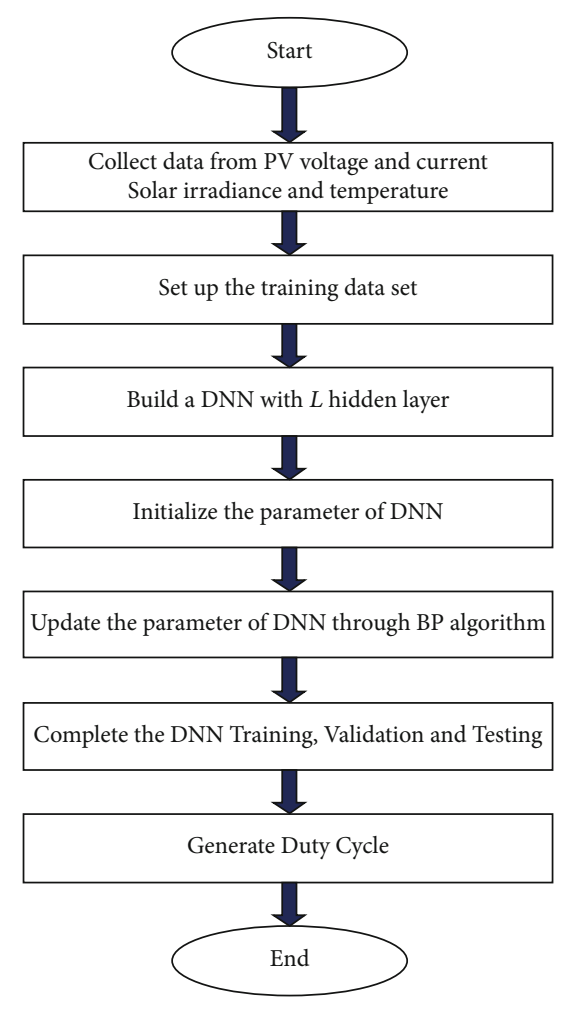

(a)

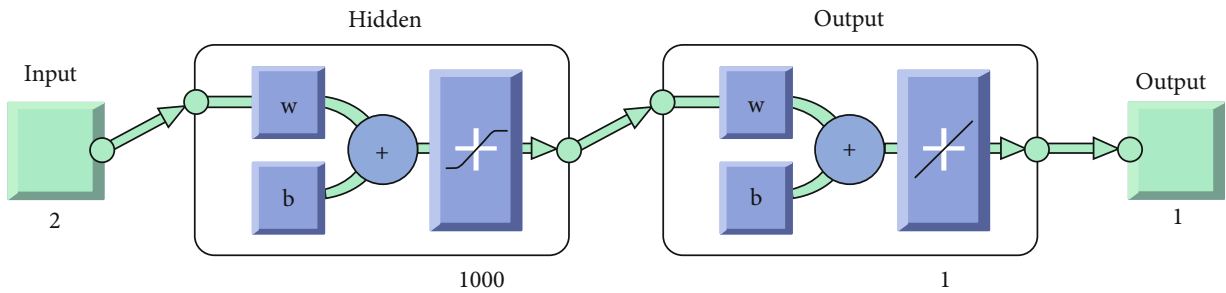

(b)

Figure 4: (a) Flow chart of the DNN model for the PV-MPPT system. (b) DNN model for the PV-MPPT system.

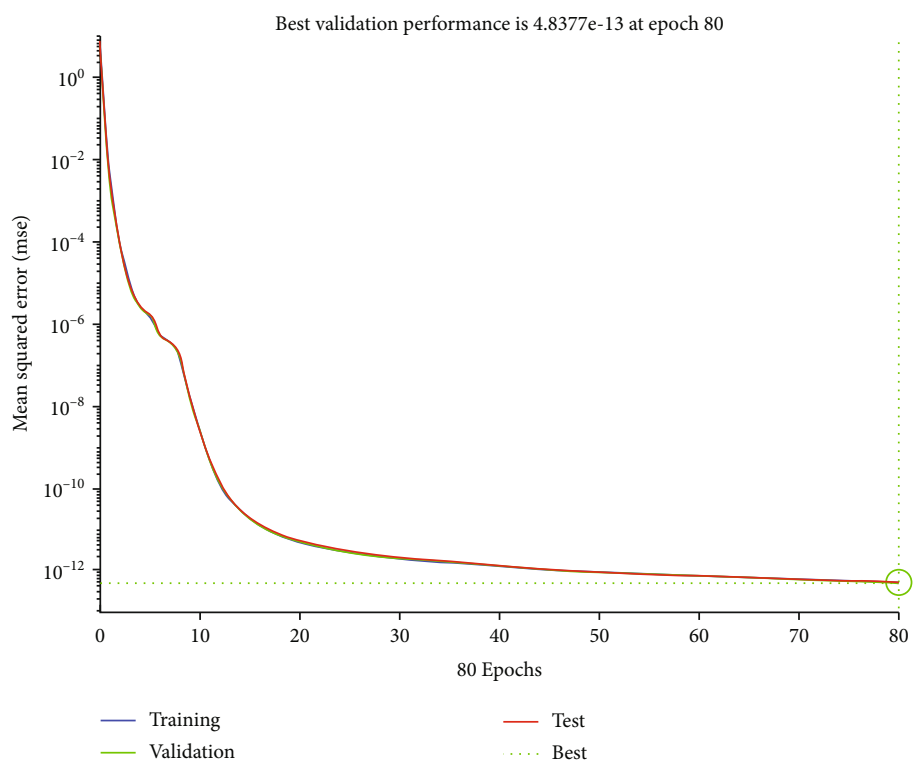

FIGURE 5: DNN-PV MPPT controller showing the best validation performance. 


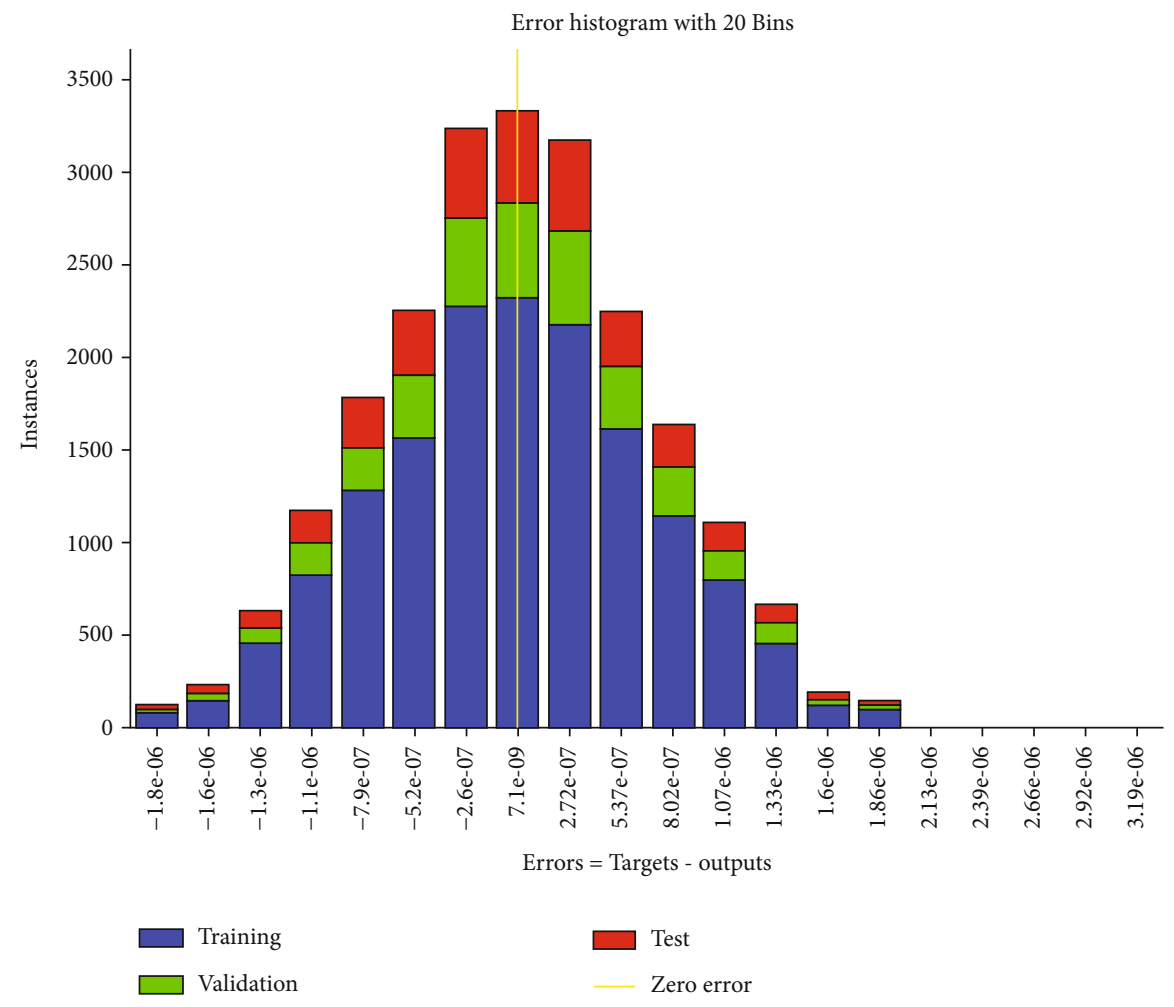

FIGURE 6: DNN-PV MPPT controller error histogram.
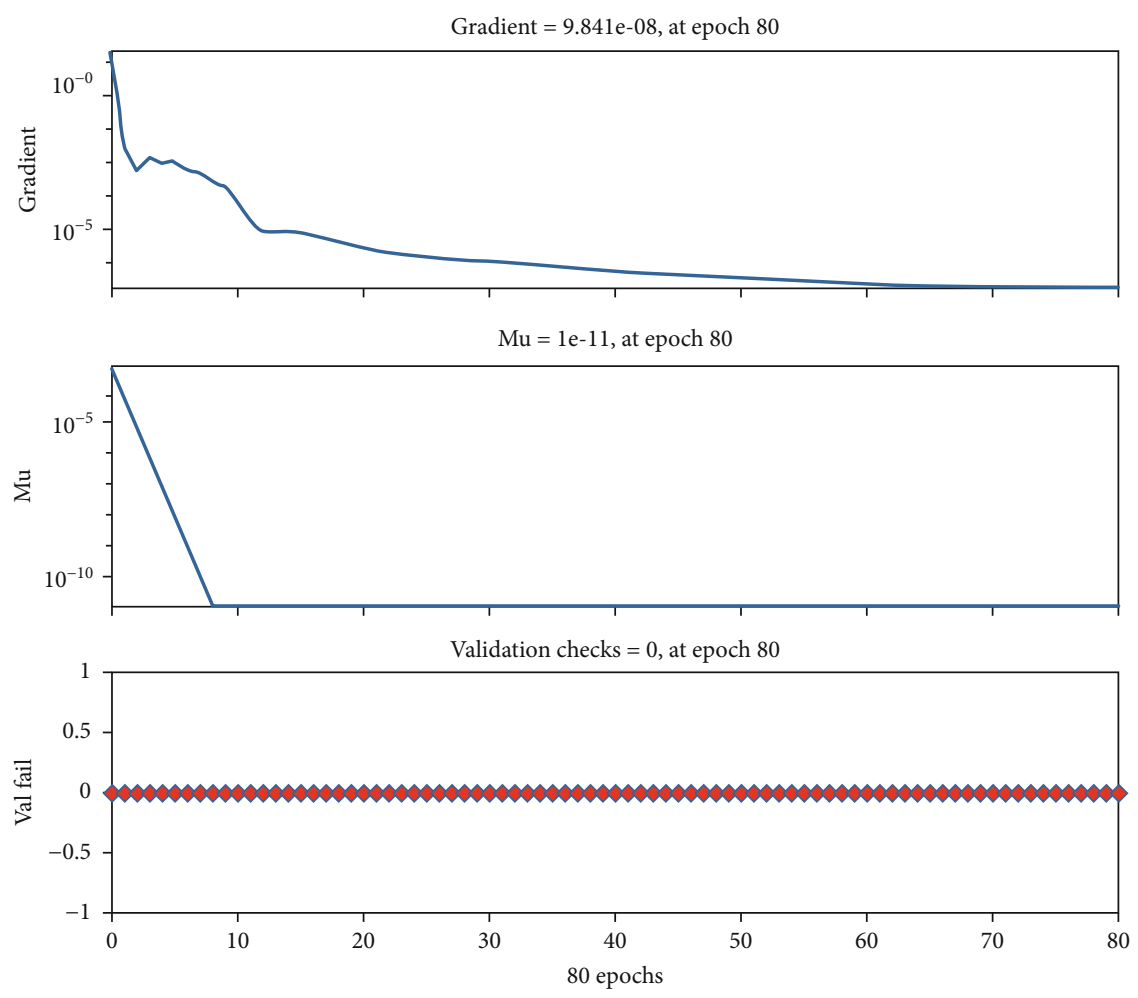

FIgURE 7: DNN-PV MPPT controller training data. 

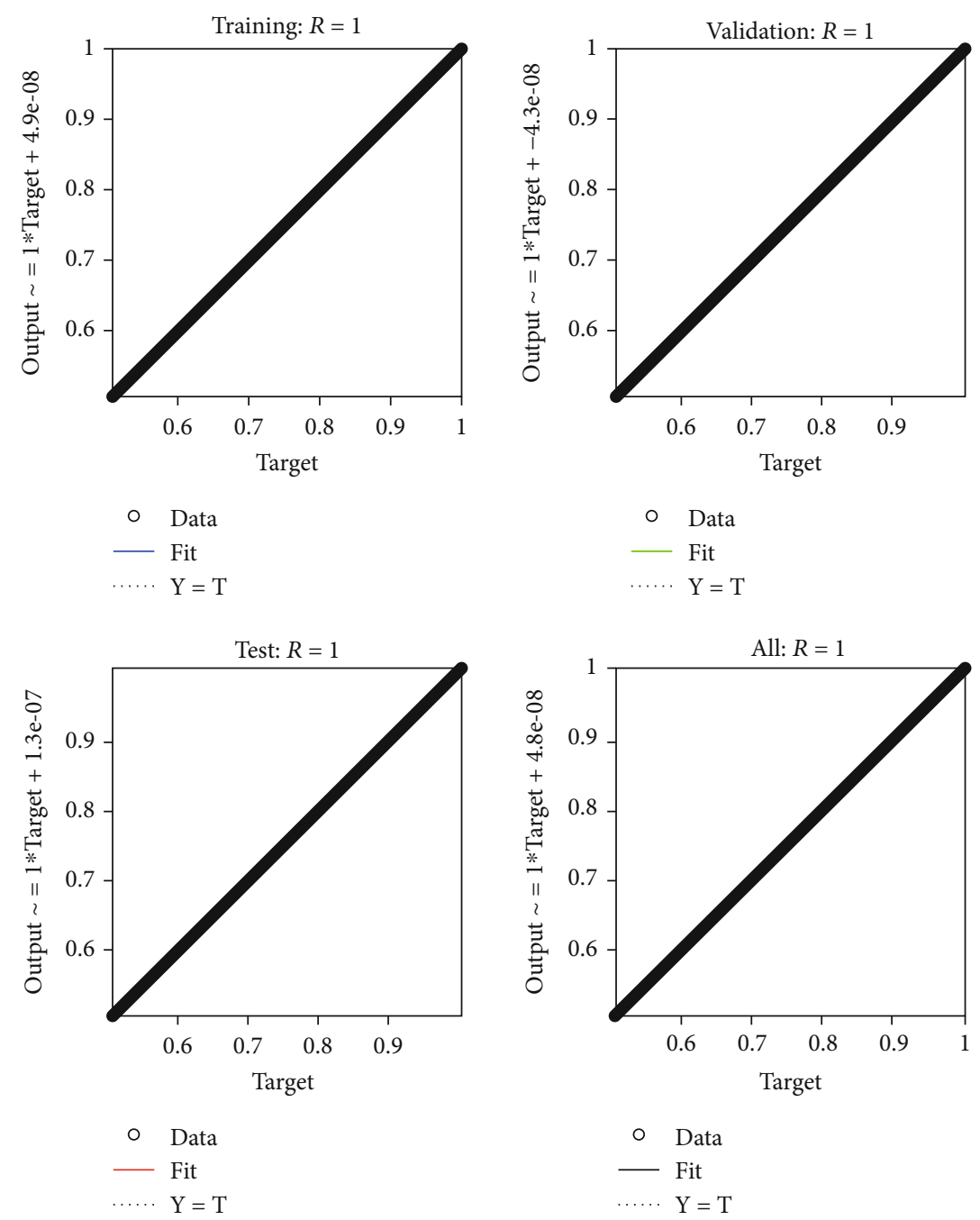

FIGURE 8: DNN-PV MPPT controller showing the best regression.

TABLE 1: DNN data of MPPT controller.

\begin{tabular}{lc}
\hline DNN-wind MPPT & Values \\
\hline Best validation & $4.8377 e-13$ \\
$\mathrm{Mu}$ & $1 e-11$ \\
Gradient & $9.841 e-11$ \\
Training & 1 \\
Validation & 1 \\
Test & 1 \\
Overall regression & 1 \\
\hline
\end{tabular}

depends on the following: (a) the complexity of network architecture, (b) the number of input and output units, (c) the number of training samples, (d) the degree of the noise in the sample dataset, and (e) the training algorithm.

If the number of samples in the dataset is too small or the data is not extremely noisy, a hidden layer is generally not needed. A linear or generalized linear model may be sufficient to obtain the training and prediction accurately [3]. The hidden neuron can impact the error on the nodes to which their output is connected. The stability of neural network is assessed by error. The minimal error imitates better stability, and higher error imitates the worst stability. The unnecessary hidden neurons will cause overfitting; that is, the neural networks have overestimated the complexity of the target problem. The proposed DNN trained network gradient and validation check is presented in Figure 7. Finally, the proposed DNN-based MPPT algorithm has been developed, and its best regression is presented for training data, test data, validation data, and the overall performance data in Figure 8. The overall DNN data are presented in Table 1.

The proposed and developed MPPT algorithm, which is DNN-based, has been applied to a $20 \mathrm{~kW}$ PV system, which is simulated in a MATLAB environment, and analyzed under various weather influences. Figure 9 shows the PV output power with various temperature and irradiance values. The boost converter's current waveform and output voltage are shown in Figure 10. 

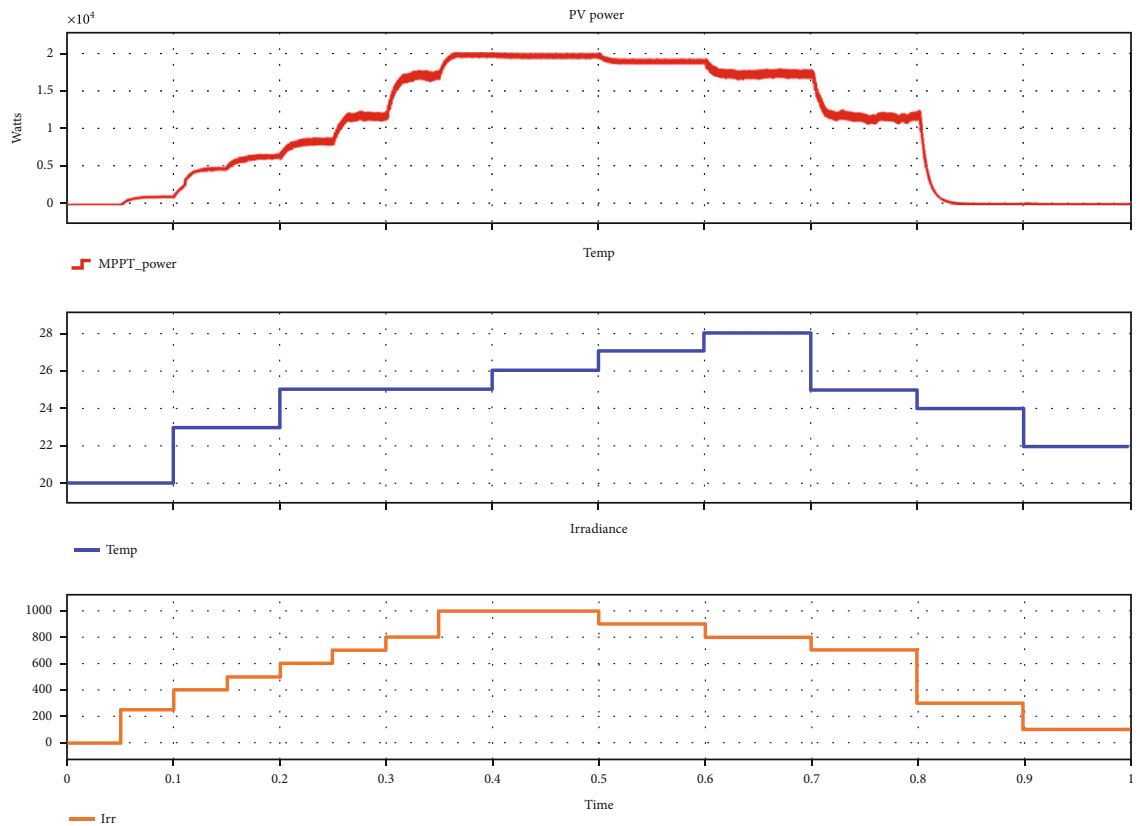

FIGURE 9: Simulation results of DNN-PV MPPT power with respect to irradiance and temperature.

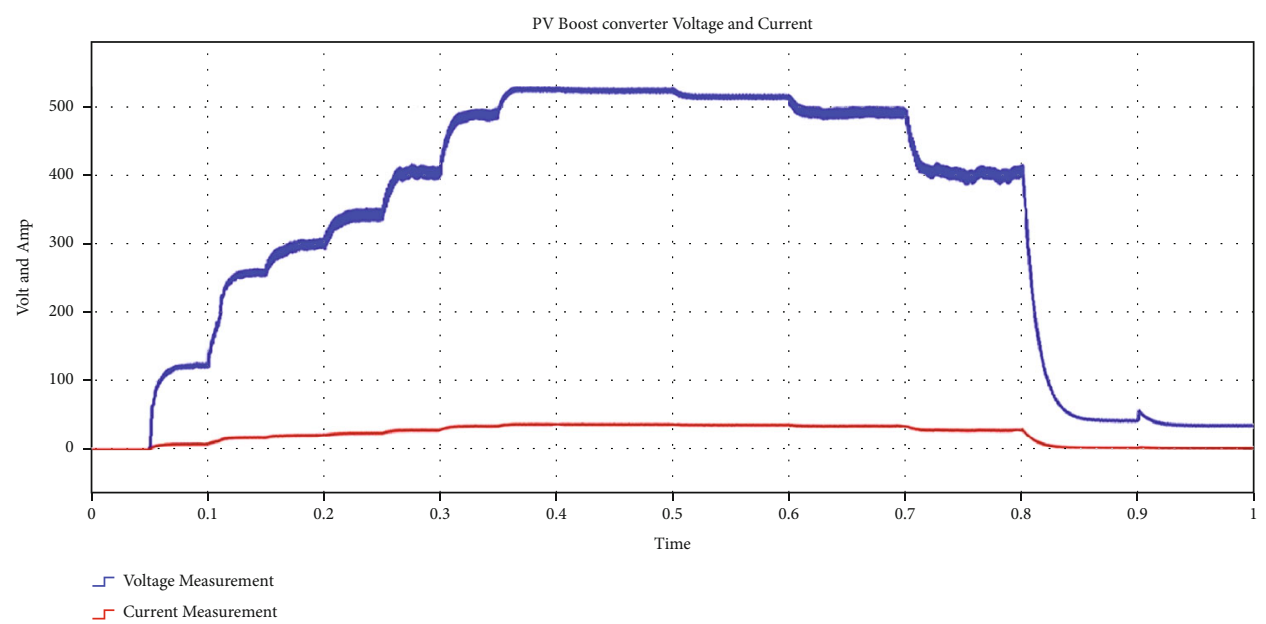

FIgURE 10: Simulation results of DNN-PV MPPT boost converter voltage and current with respect to irradiance and temperature.

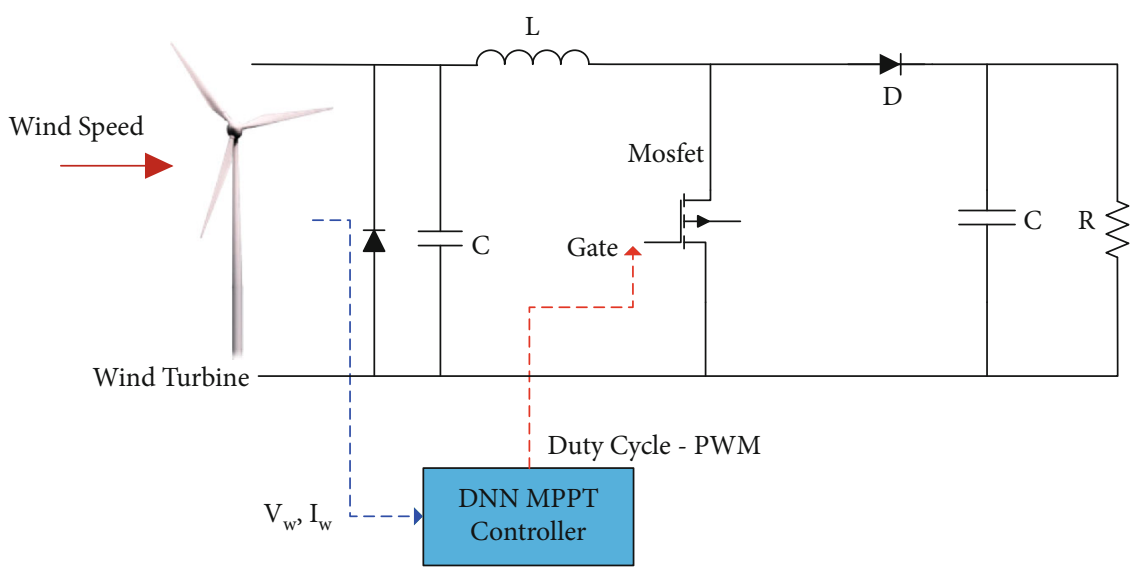

FIgURE 11: Proposed DNN-based MPPT algorithm (wind energy system). 
DL control based MPPT techniques for $30 \mathrm{~K}$ Watts wind power system

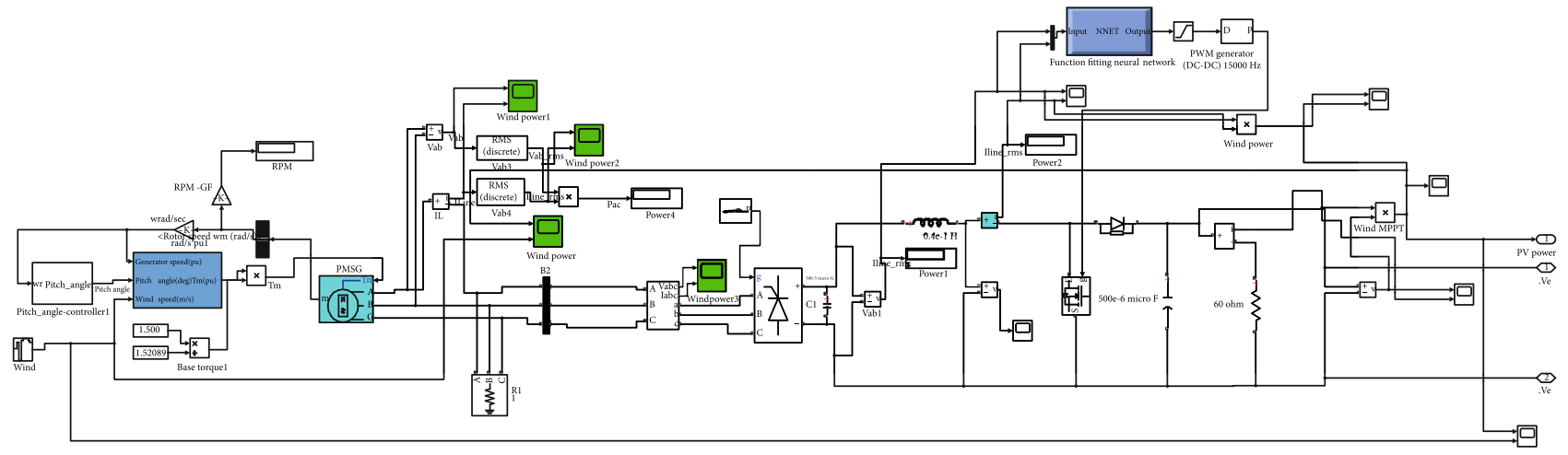

FIGURE 12: Simulation model of DNN controller-based MPPT algorithm (wind energy system).

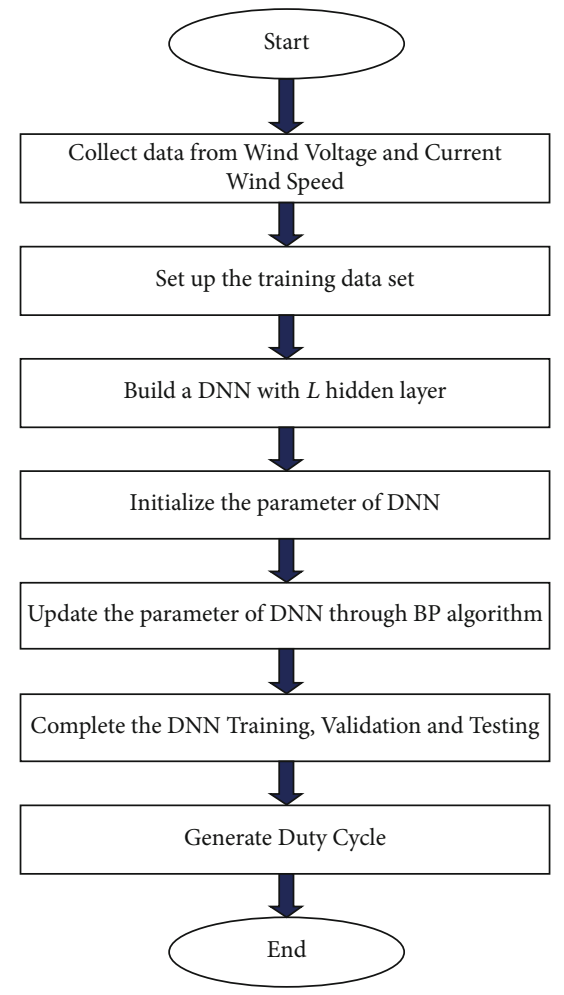

(a)

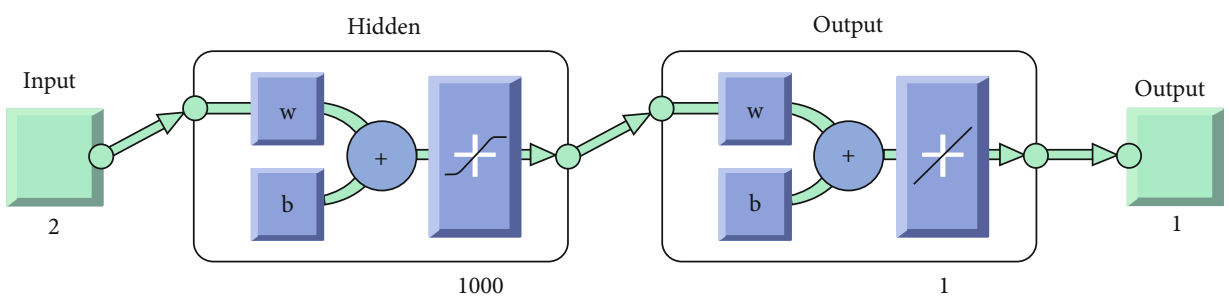

(b)

FIGURE 13: (a) Flow chart of DNN model of a wind-based MPPT system. (b) DNN model of a wind-based MPPT system. 
Best validation performance is $3.597 \mathrm{e}-11$ at epoch 108

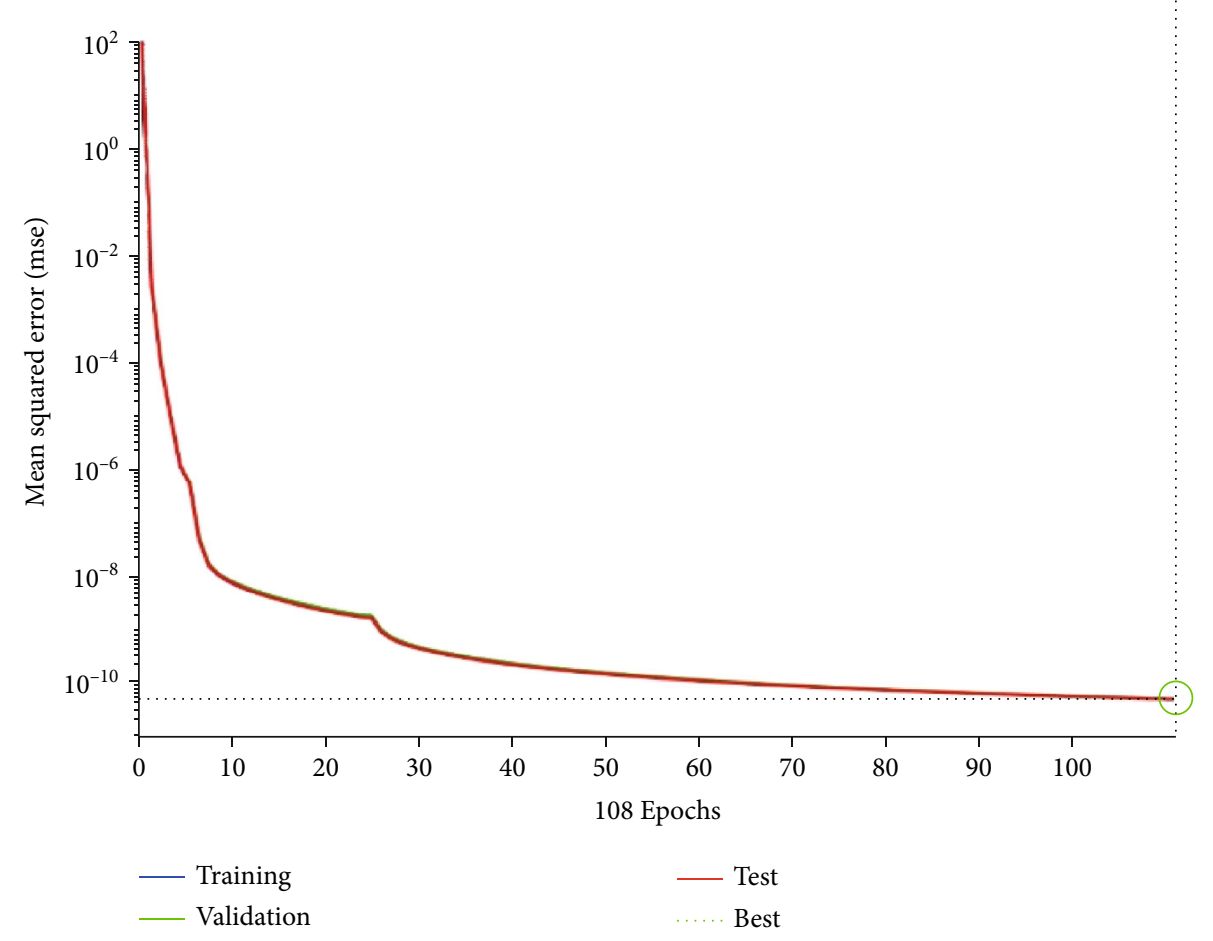

Figure 14: The best validation performance of a DNN-wind MPPT controller.

\section{Deep Neural Network-Based MPPT for Wind Power Systems}

We used a DNN controller to develop the mentioned MPPT algorithm for a wind conversion energy system, as shown in Figure 11. In this DNN learning algorithm, 66000 data are used for providing training to develop the MPPT algorithm [12]. The simulation model of the proposed MPPT-based system was simulated using MATLAB, as shown in Figure 12. In the simulation of the proposed model, a $30 \mathrm{~kW}$ wind energy system has been used and a boost converter is also used for stepping up voltage [23]. In Figure 13(a), the flow chart of the DNN controller is presented, and the DNN layer is presented in Figure 13(b). This layer has two input neurons while there are 1000 hidden-layer neurons and just one output neuron. This DNN layer has been used for training MPPT network with the help of input data (wind voltage, wind current), and the output was obtained as the duty cycle of the converter.

The DNN controller has been trained using the above system, and its best validation performance is presented in Figure 14. The proposed DNN controller error (target-output) and its histogram data are presented in Figure 15. The proposed DNN trained network gradient and validation check are presented in Figure 16. Finally, the proposed DNN-based MPPT algorithm has been developed and presented with its best regression for training data, test data, validation data, and overall performance data in Figure 17. Regression predicts an output variable (duty cycle), which is a function of a couple of inputs (current and wind voltage). The overall DNN data are presented in Table 2.

The proposed and developed DNN-based MPPT algorithm has been applied on a $30 \mathrm{~kW}$ wind energy system and simulated. The proposed MPPT system was analyzed with respect to various wind speeds. Figure 18 presents the wind energy system output power at various wind speeds. The boost converter's output voltage and the current waveform are presented in Figure 19. The output of the wind energy system with and without DNN-based MPPT controller has been displayed in Figure 20.

\section{Microgrid Integration with a Hybrid PV/Wind Power System}

In this section, we have explained the microgrid integration with a hybrid PV/wind-based power system, which has been developed and controlled by the DNN-based MPPT algorithm $[24,25]$. The detailed simulation model is presented in Figure 21. This simulation model uses a hybrid $50 \mathrm{~kW} \mathrm{PV}$. The wind energy system is integrated into power microgrid with the support of a smart inverter, which is controlled by a DNN-based voltage source controller [26, 27]. In this controller, there are three designed major subcontrollers, which include a phase-lock loop, a current regulator, and a voltage regulator (Figure 22). Finally, the PWM signals are generated through a current regulator for a smart inverter that synchronizes a $50 \mathrm{~kW}$ hybrid PV/wind and microgrid system. 


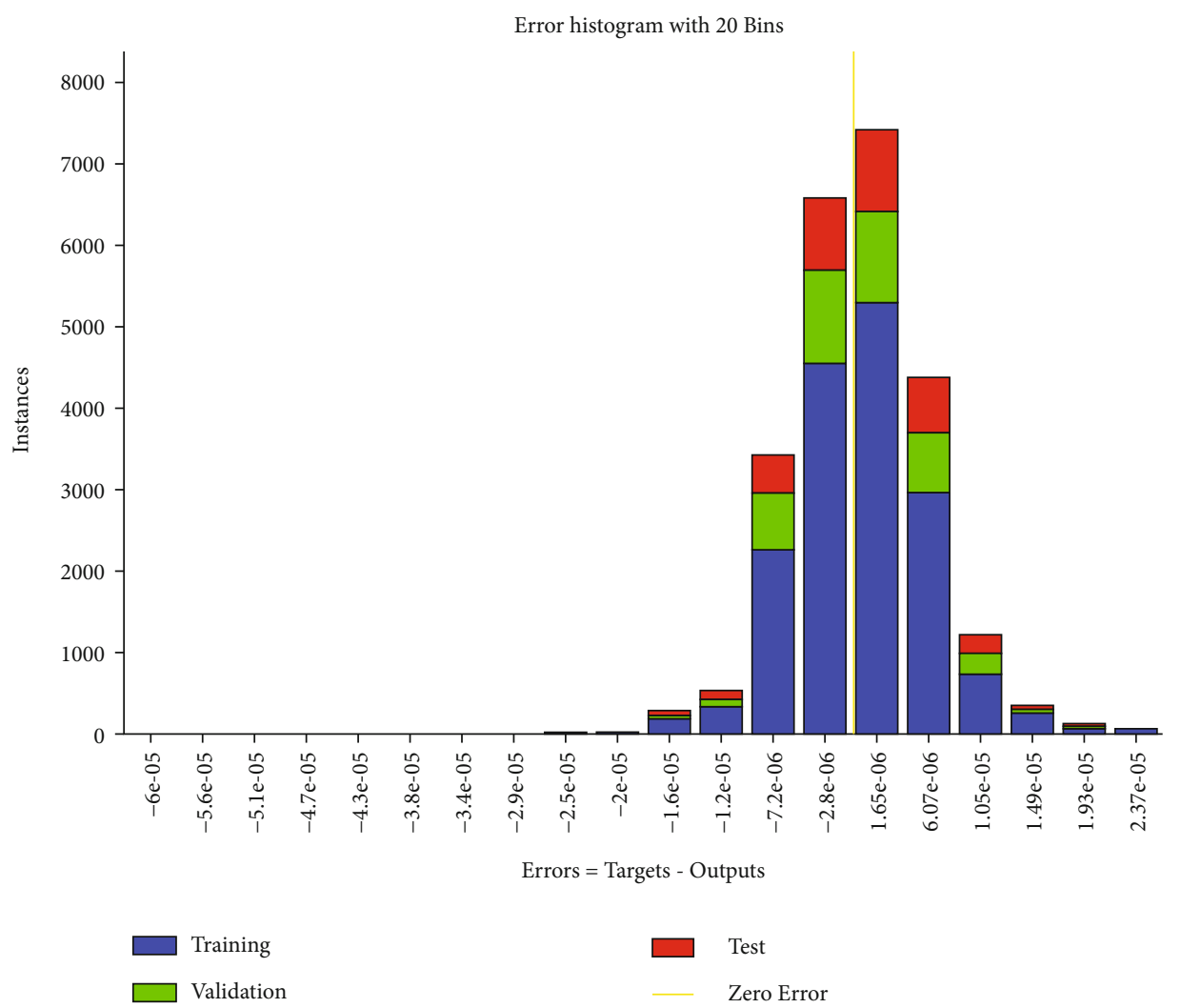

FIGURE 15: Histogram of the DNN-wind MPPT controller.
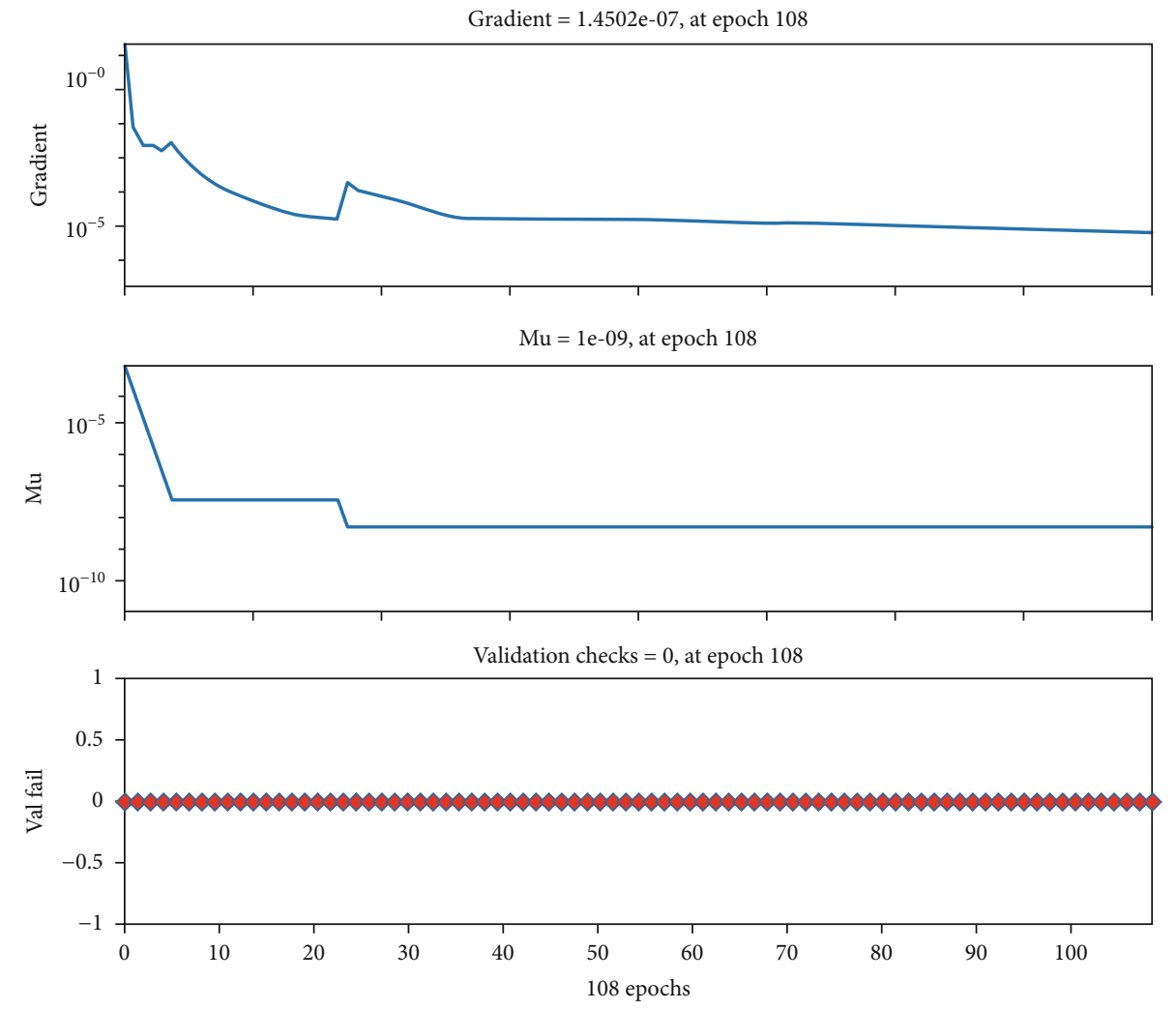

FIgURE 16: Training data of the DNN-wind MPPT controller. 

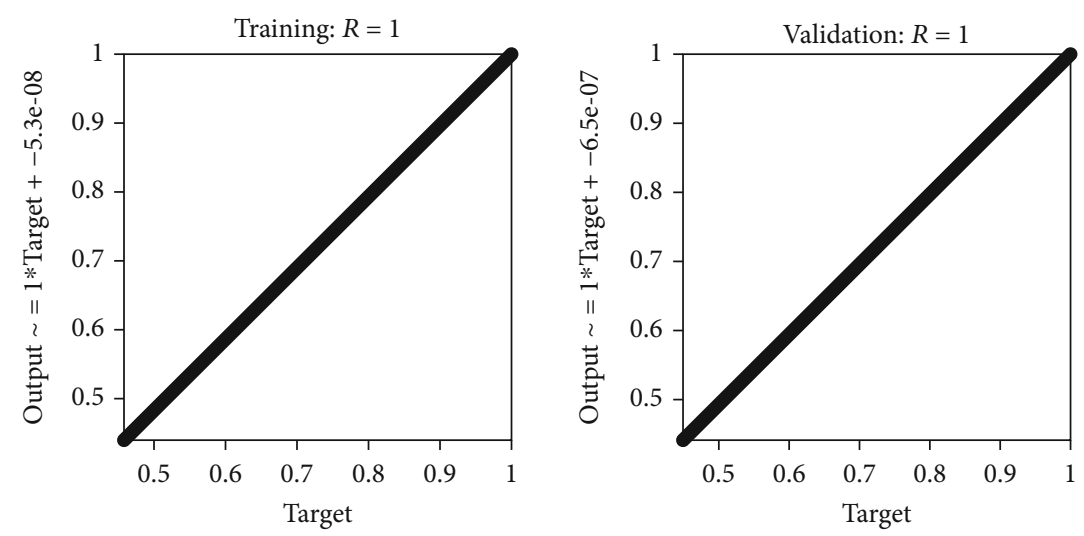

$$
\begin{array}{ll}
\circ & \text { Data } \\
- & \text { Fit } \\
\cdots & \mathrm{Y}=\mathrm{T}
\end{array}
$$
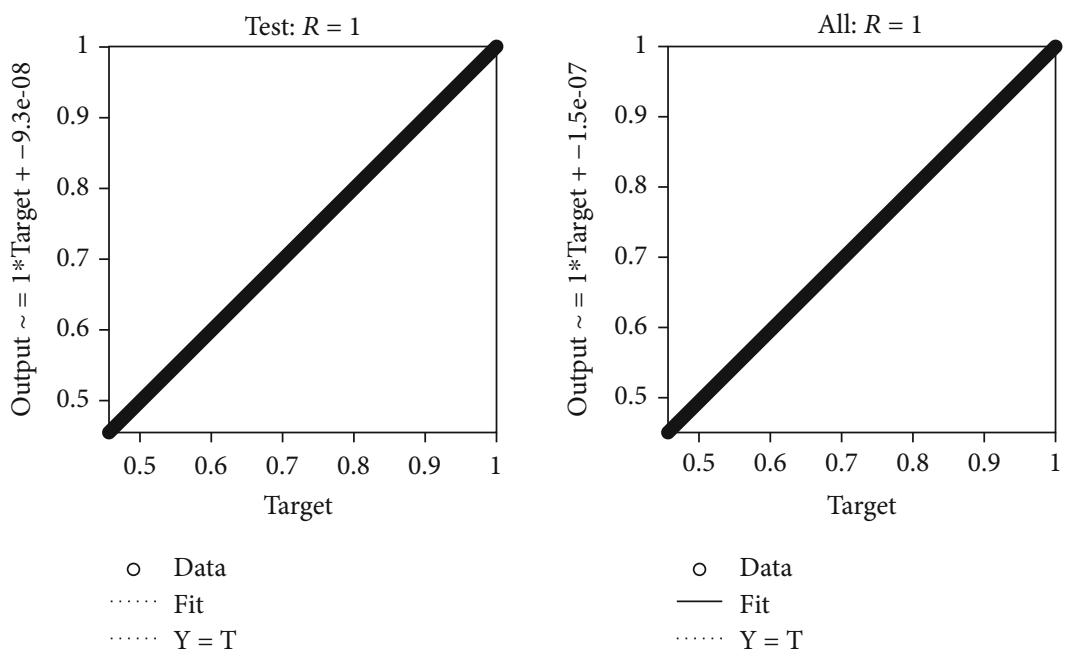

FIgURE 17: Training and validation of a DNN-wind MPPT controller.

TABLE 2: DNN data of an MPPT controller for a wind system.

\begin{tabular}{lc}
\hline DNN-wind MPPT & Values \\
\hline Best validation & $3.597 e-11$ \\
$\mathrm{Mu}$ & $1 e-9$ \\
Gradient & $1.4502 e-7$ \\
Training & 1 \\
Validation & 1 \\
Test & 1 \\
Overall regression & 1 \\
\hline
\end{tabular}

\section{Deep Neural Network (DNN) Controller- Based Grid-Integrated Smart Inverter}

The deep neural network (DNN) controller has been used to develop a current regulator controller for a hybrid gridconnected PV and wind energy system using smart inverter. As mentioned earlier, this DNN learning algorithm used
60000 data items for developing a current regulator algorithm. The simulation model of the proposed current regulator-based grid-connected smart inverter has been simulated using MATLAB (Figure 23).

Figures 24(a) and 24(b) show the flow chart and DNN layer with 2 input neurons, 2000 hidden-layer neurons, and an output neuron. This DNN layer has been used for training a current regulator network, using the following data: input (direct axis and quadrant axis for current) and output is in the form of PWM signals for a grid-integrated smart inverter.

The DNN controller has been trained with the above system and its best validation performance has been presented in Figure 25. The proposed DNN controller error (target-output) histogram data is presented in Figure 26. The proposed DNN-trained network gradient and validation check is presented in Figure 27. Finally, the proposed DNN-based current regulator algorithm has been developed and presented with its best regression for training data, test data, validation data, and the overall performance data shown in Figure 28. Regression ANNs predict an output variable (PWM) as a function of the inputs (observed direct and quadrant axis current). The overall DNN data are presented in Table 3. 

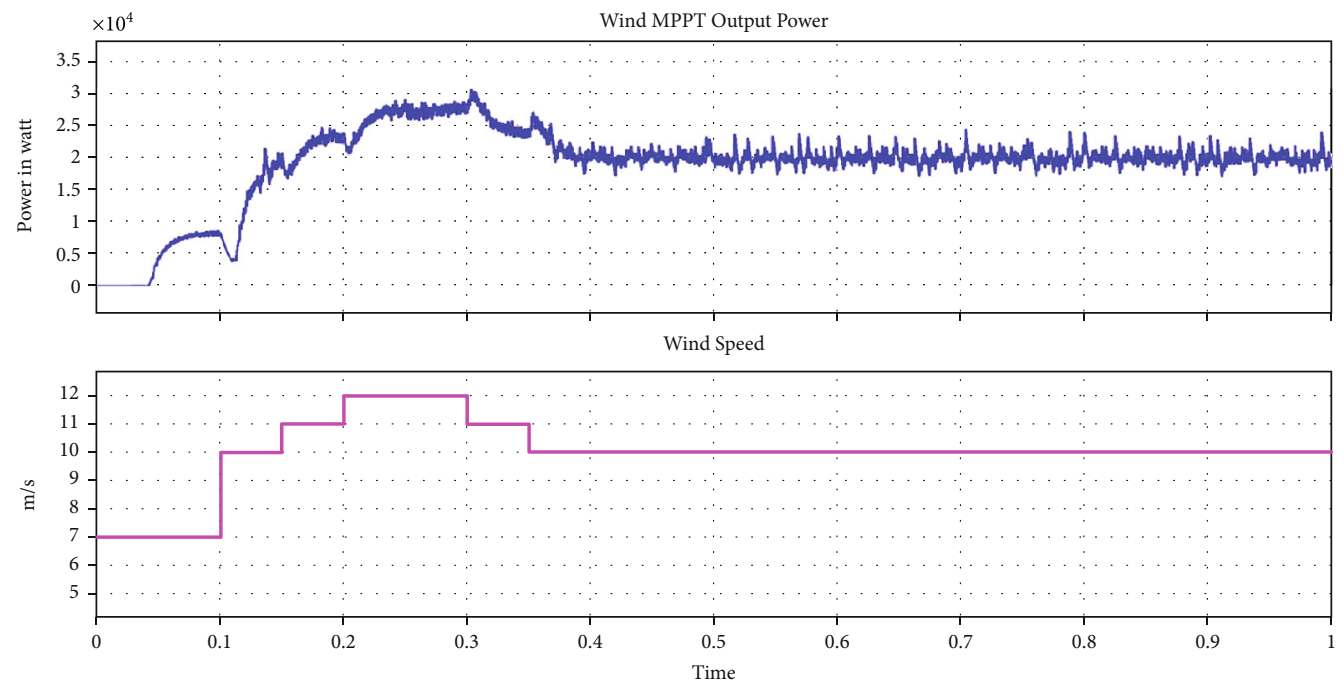

FIGURE 18: Simulation results of DNN-wind MPPT power (for different wind speeds).

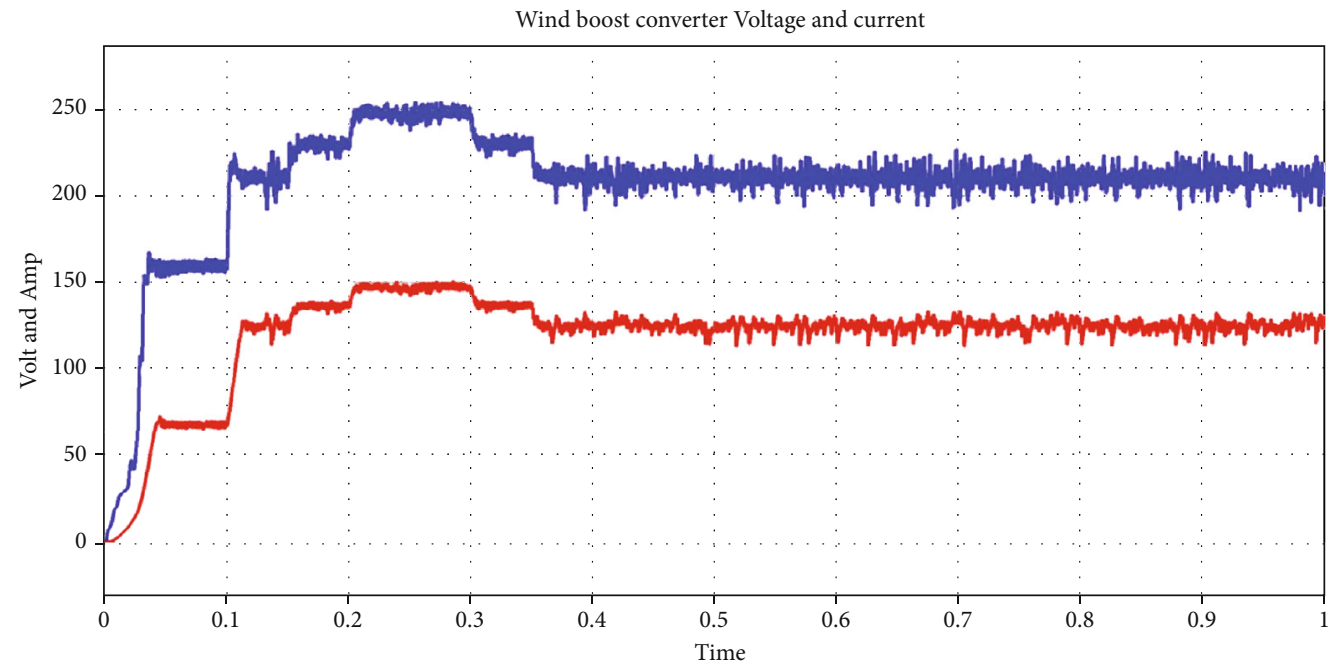

FIGURE 19: Simulation results for DNN-wind MPPT converter voltage and current (for different wind speeds).

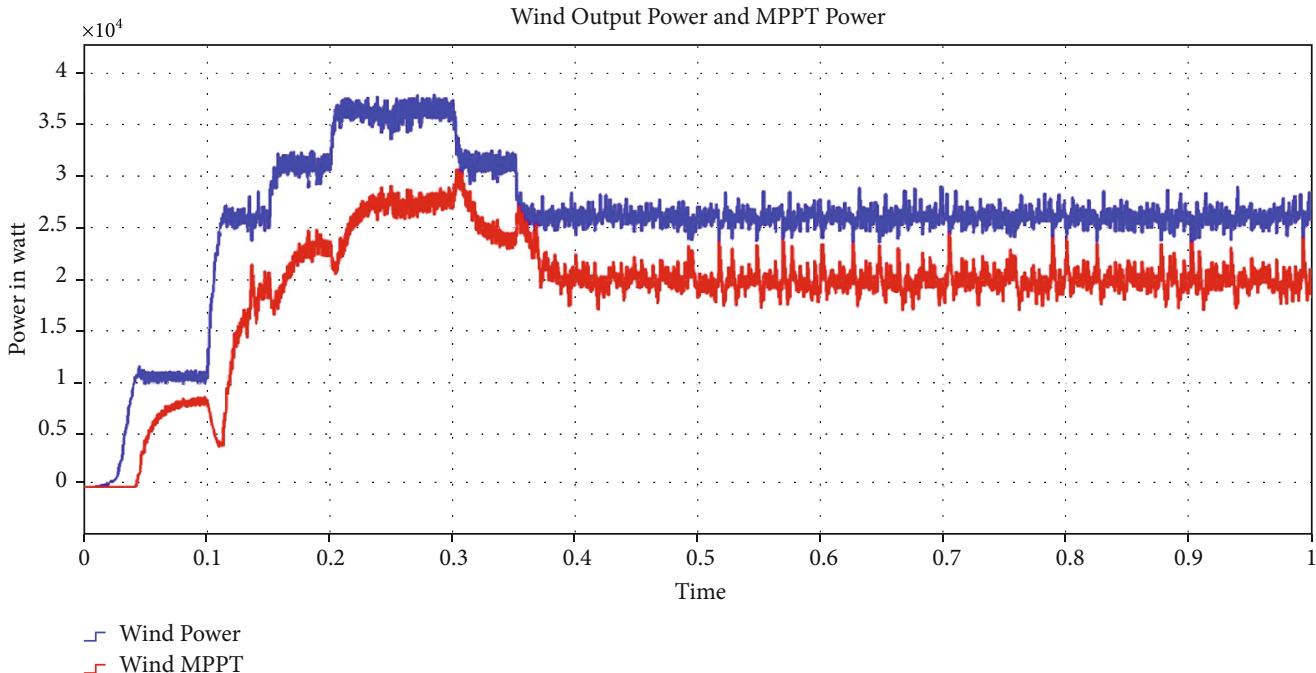

FIgURE 20: Comparative analysis with and without wind MPPT power (for different wind speeds). 


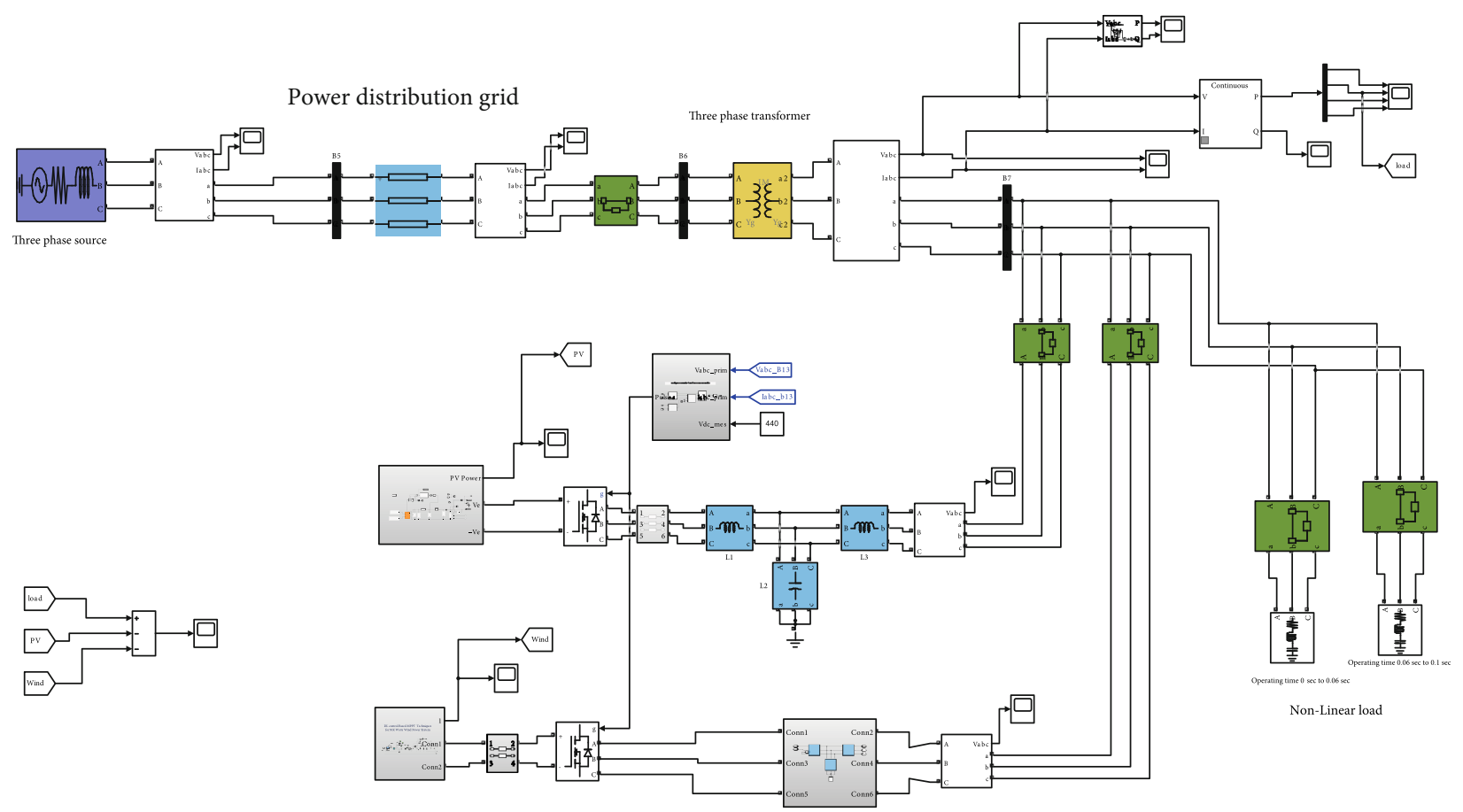

Figure 21: Proposed simulation model of the DNN controller-based microgrid integrated with a hybrid PV/wind energy system.

Intelligent controller based VSC main controller

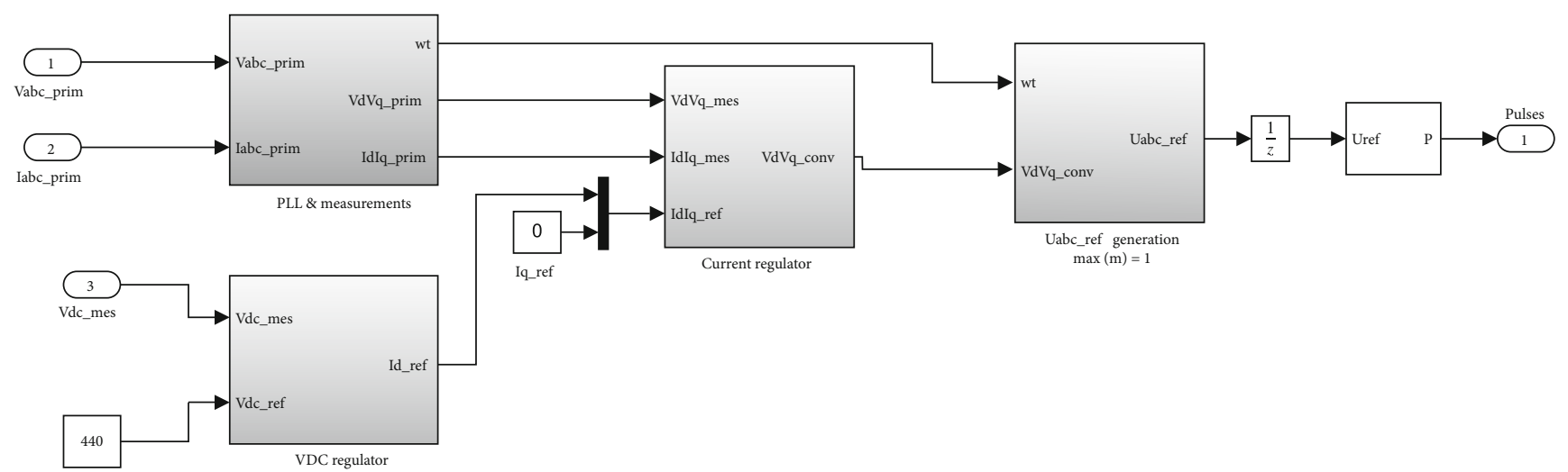

FIGURE 22: DNN controller-based voltage source controller for smart inverters.

\section{Results and Discussion}

First, we proposed and developed a system and then simulated it using MATLAB for different operating conditions. The mentioned simulation provided the data and results, which were noted. Figure 29 shows that the real power consumed by the consumer's load from the microgrid network was $170 \mathrm{~kW}$. The reactive power consumed by the consumer's load from the microgrid was around $220 \mathrm{kVR}$, as shown in Figure 30. Figure 31 shows the total power generated by a hybrid PV/wind energy system. We conducted the analysis mainly to maintain microgrid grid voltage and current without any oscillation. Figure 32 shows the microgrid voltage and current waveform under grid-integrated nonlinear power-generating source in connection with the hybrid PV/wind energy system. The major task is power management at the power-generating stations depending on consumer demand, but in this proposed model, the hybrid $\mathrm{PV} /$ wind generated almost $40 \mathrm{~kW}$ power. The power supplied by just the microgrid to the consumer load is presented in Figure 33. In this research work, another major task was to improve the power quality and reduce the THD value at the point of common coupling. This simulation work deeply analyzes the THD values of all the generating sources 


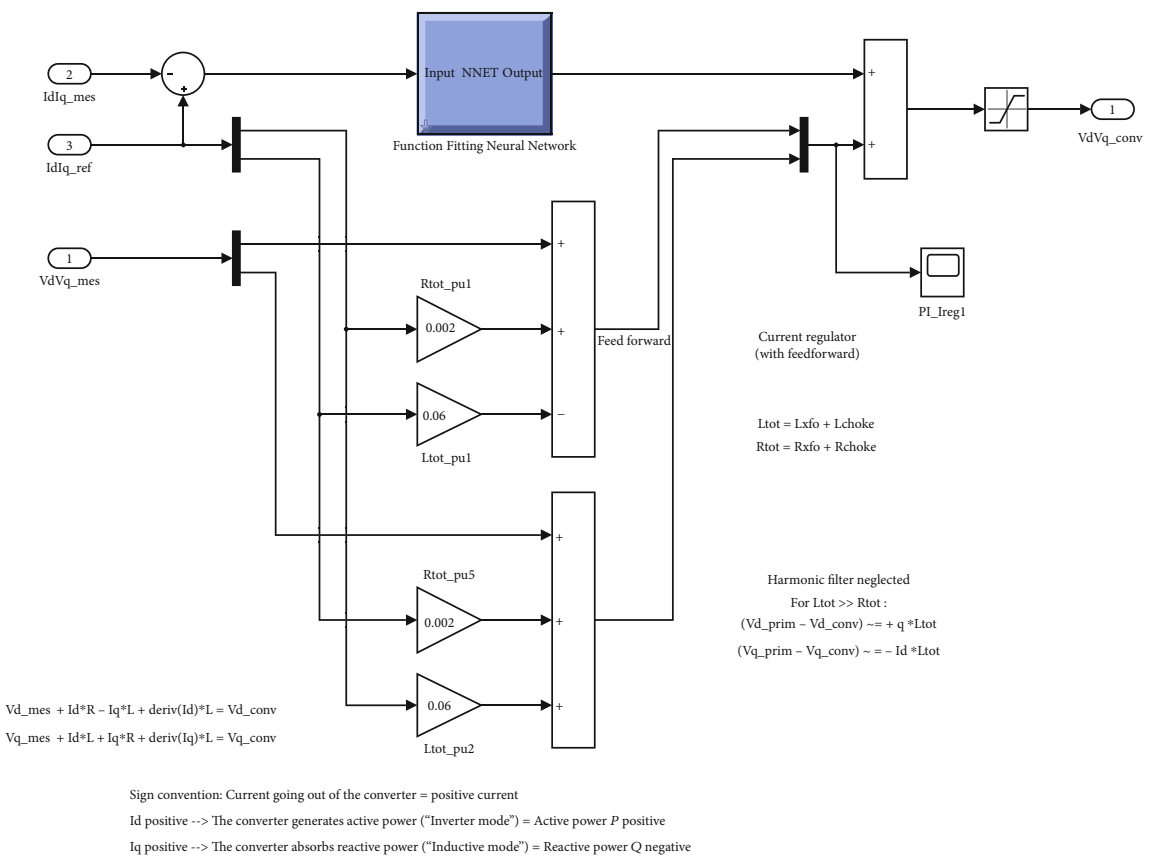

FIGURE 23: DNN-based current regulator for smart inverter.

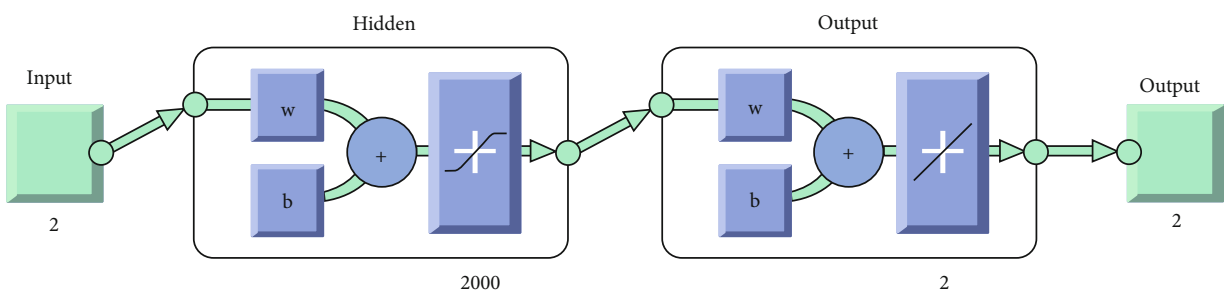

(a)

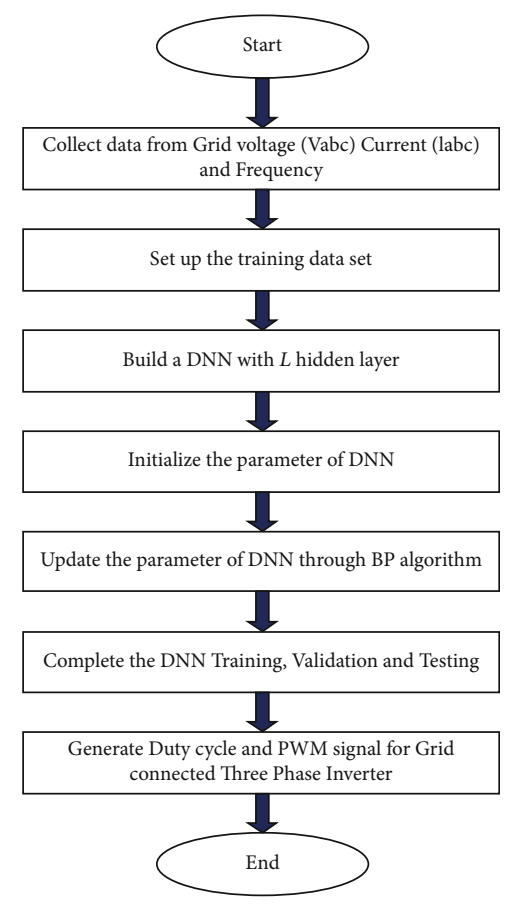

(b)

FIGURE 24: (a) DNN model of a current regulator for smart inverters. (b) Flow chart of DNN model of a current regulator for smart inverters. 


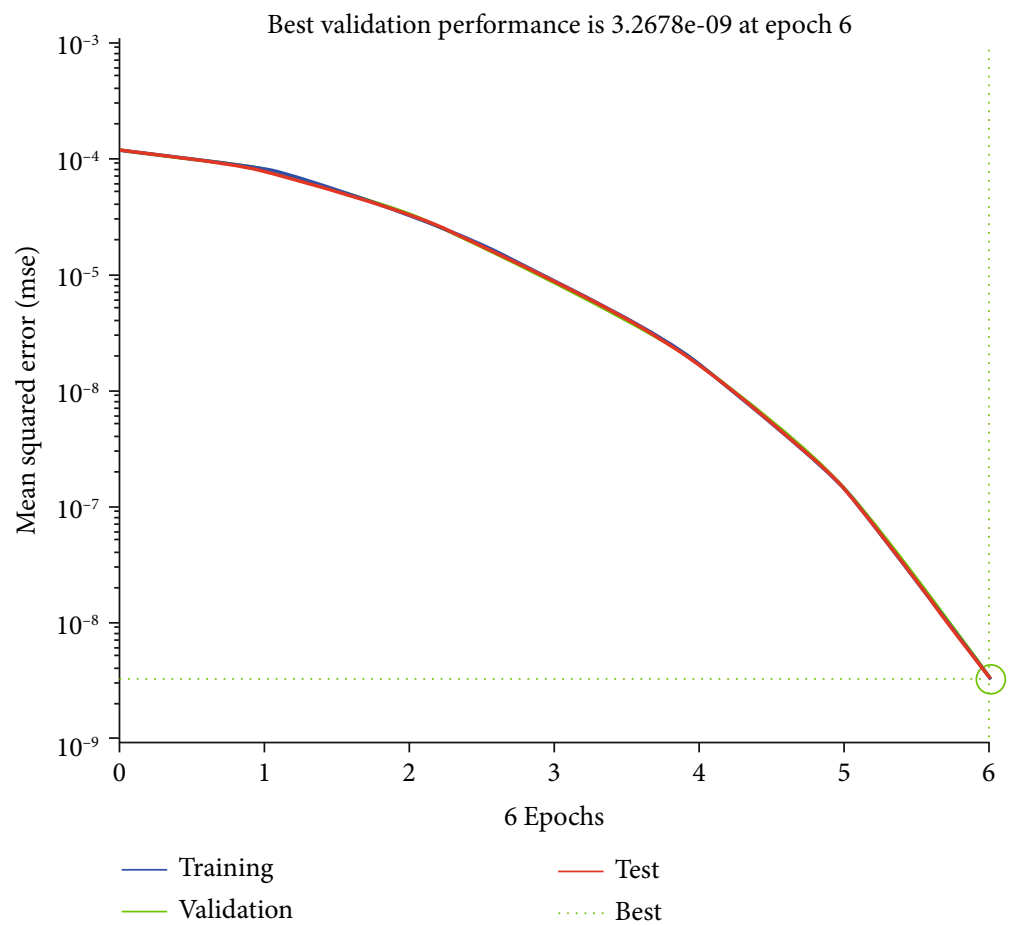

FIGURE 25: DNN-current regulator's best validation performance.

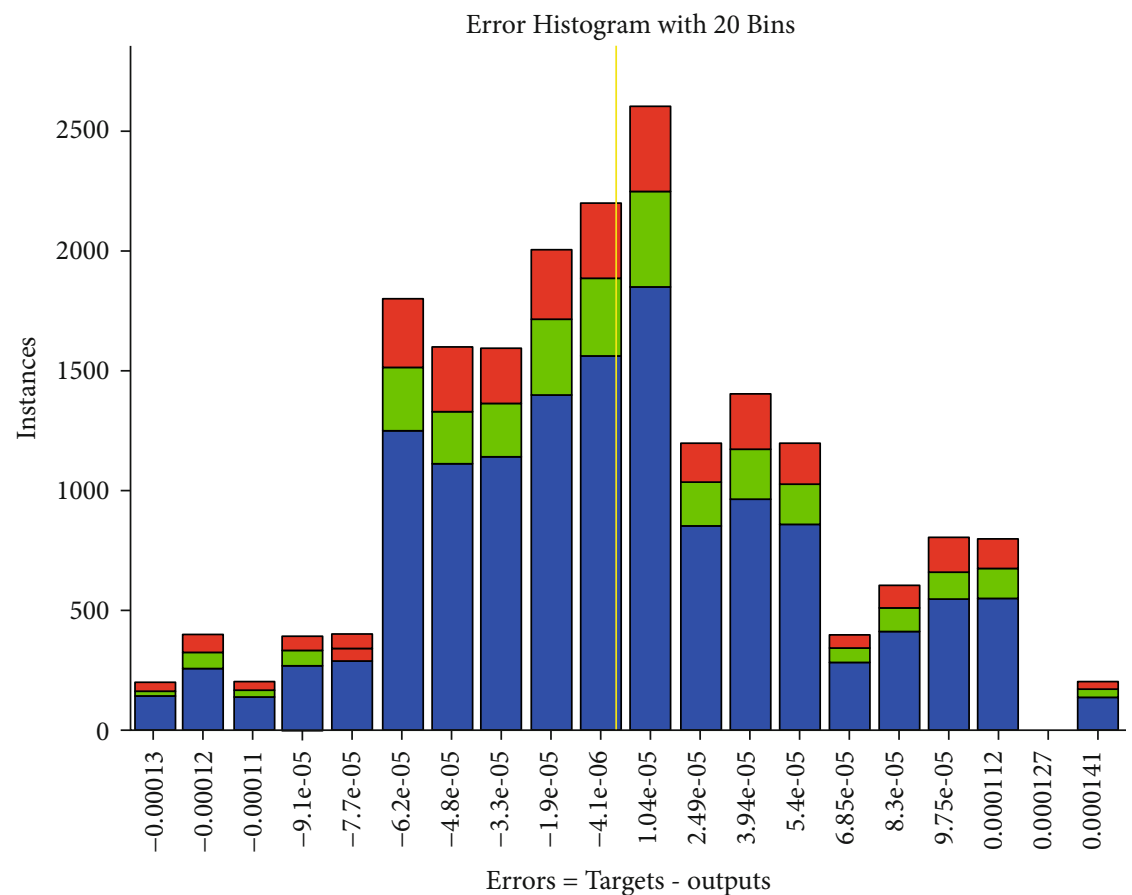

Training

$\square$ Test

Validation

Zero error

FIGURE 26: Histogram of DNN-current regulator error. 

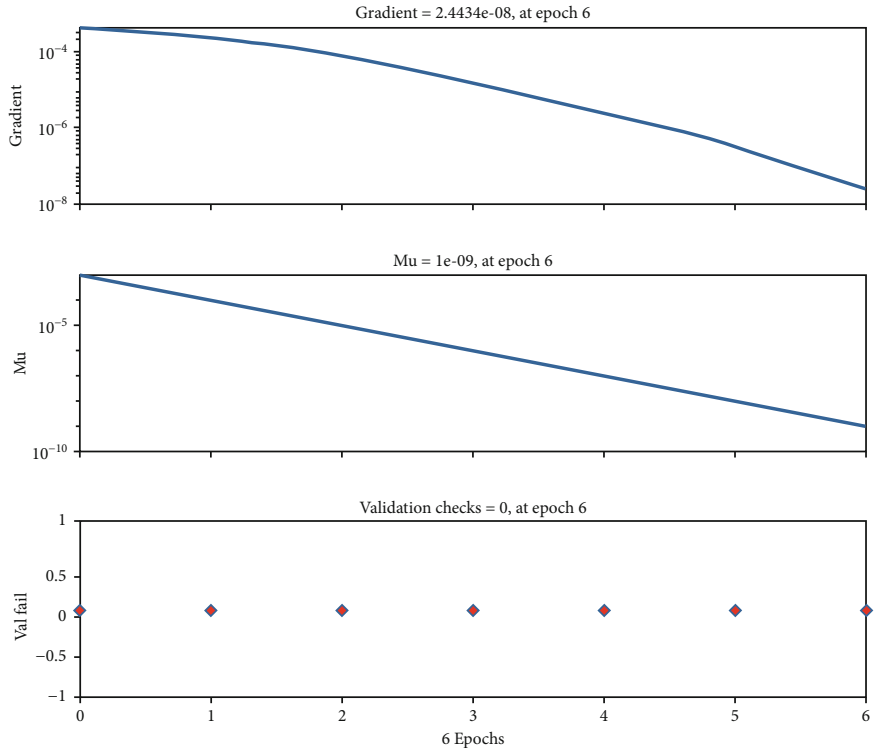

Figure 27: Training data for the DNN-current regulator.
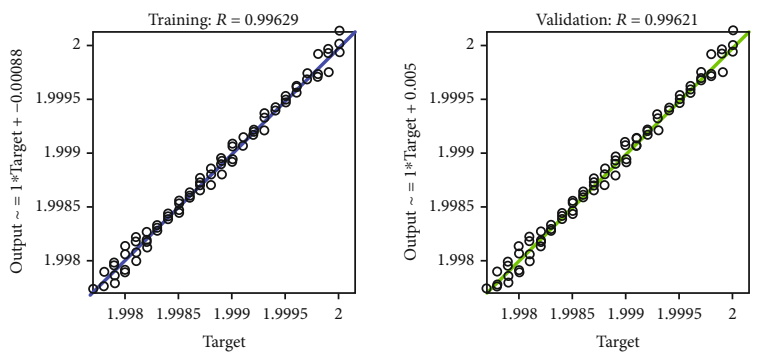

$$
\begin{aligned}
& \text { Data } \\
& \text { Fit } \\
& \text { F. }
\end{aligned}
$$

- Data

Fit
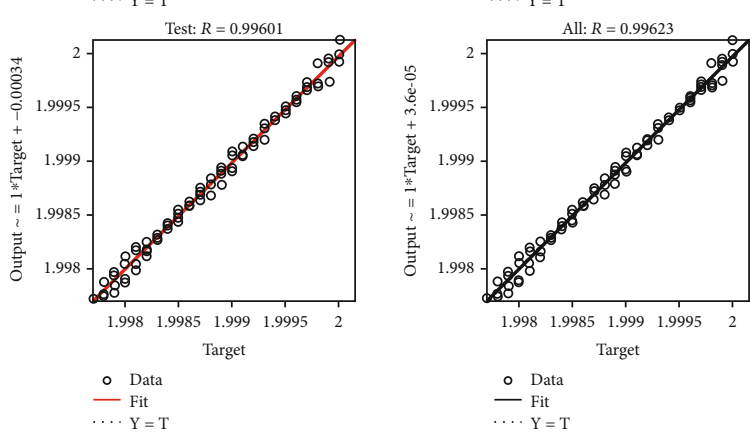

FIgURE 28: Test, training, and validation of a DNN-current regulator.

TABLE 3: DNN data of the grid system controller.

\begin{tabular}{lc}
\hline DNN grid & Values \\
\hline Best validation & $3.2678 e-9$ \\
$\mathrm{Mu}$ & $1.0 e-9$ \\
Gradient & $2.4434 e-8$ \\
Training & 0.99629 \\
Validation & 0.99621 \\
Test & 0.99601 \\
Overall regression & 0.99623 \\
\hline
\end{tabular}

and the microgrid. The PV system's THD values for voltage and current have been presented in Figures 34 and 35, respectively. Figures 36 and 37, respectively, present the wind energy system's current and voltage THD values. Finally, the microgrid load voltage and current THD values were analyzed. They are, respectively, presented in Figures 38 and 39. Table 4 shows the THD values of the resources mentioned above.

\section{Conclusion}

This paper has successfully modeled and demonstrated an algorithm for a DNN-based MPPT controller for wind 


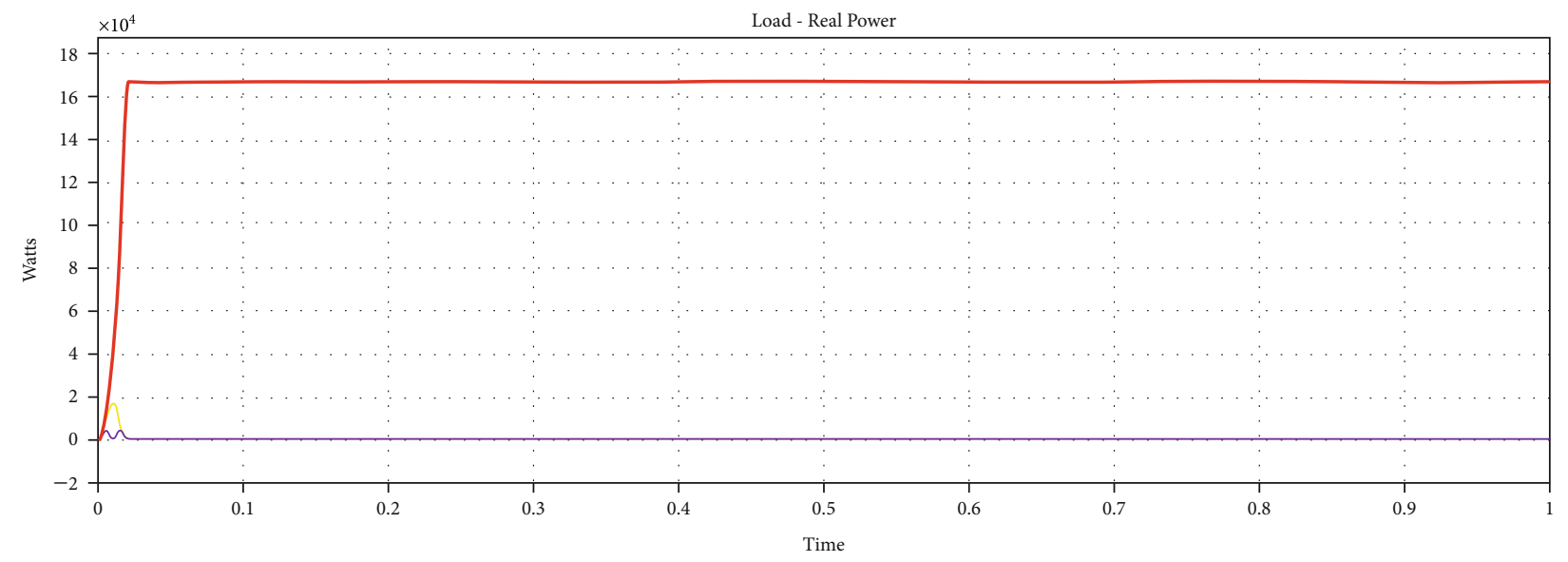

Figure 29: Real power consumed by the load.

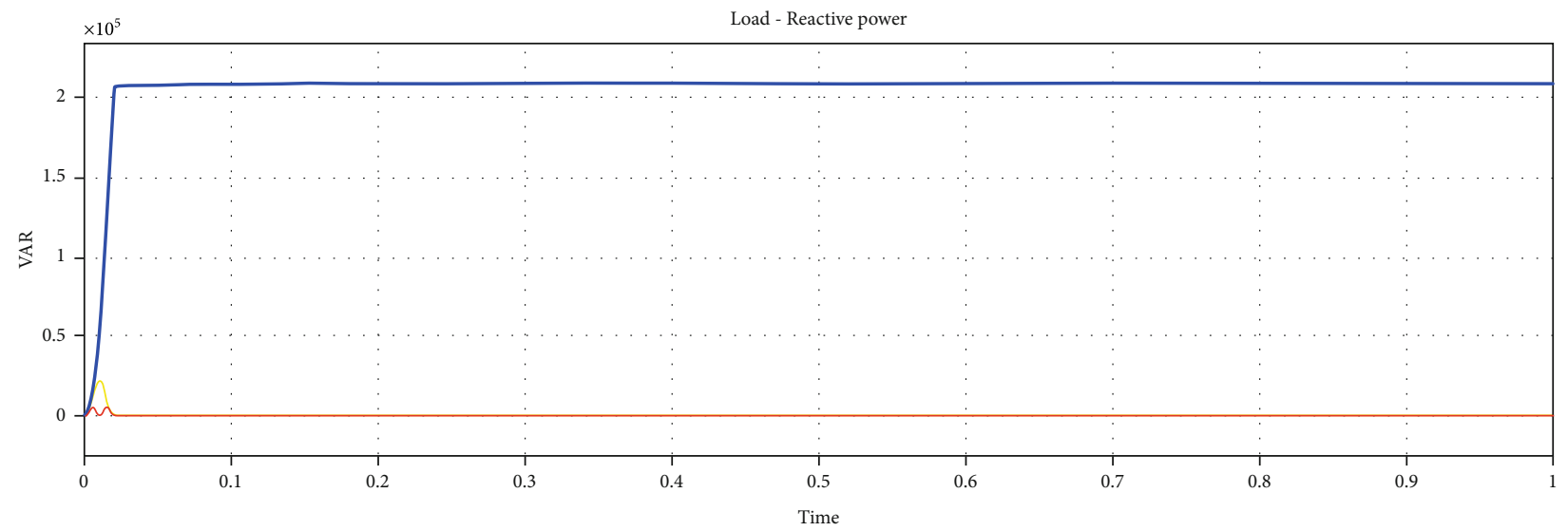

FIGURE 30: Reactive power consumed by the load.

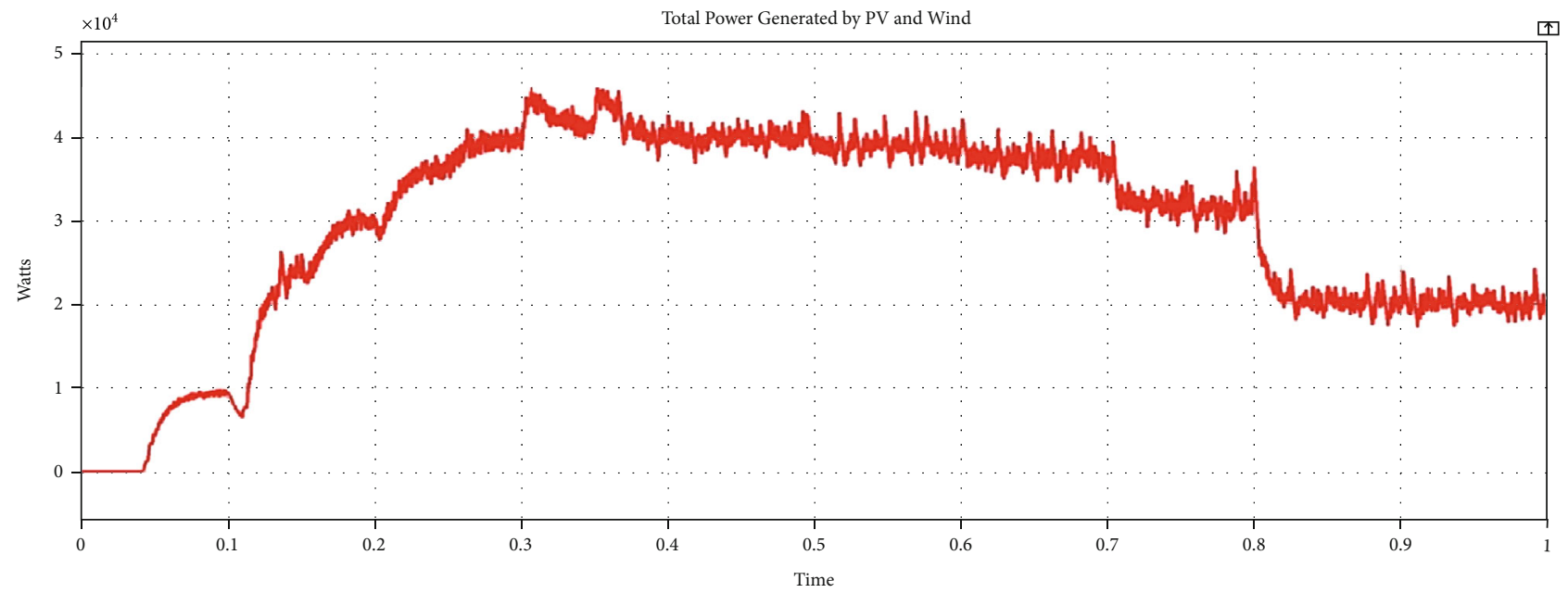

FIGURE 31: Total power generated by the hybrid PV/wind energy system. 

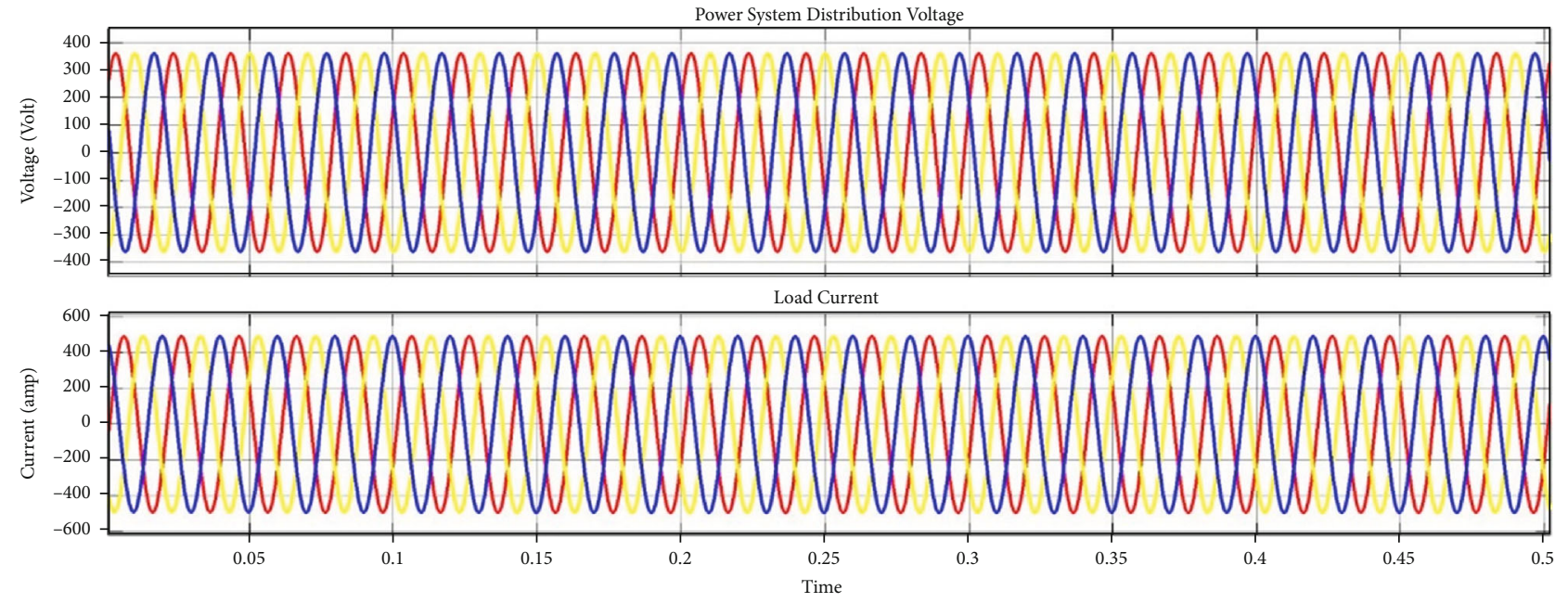

FIgURE 32: Current waveform and microgrid voltage.

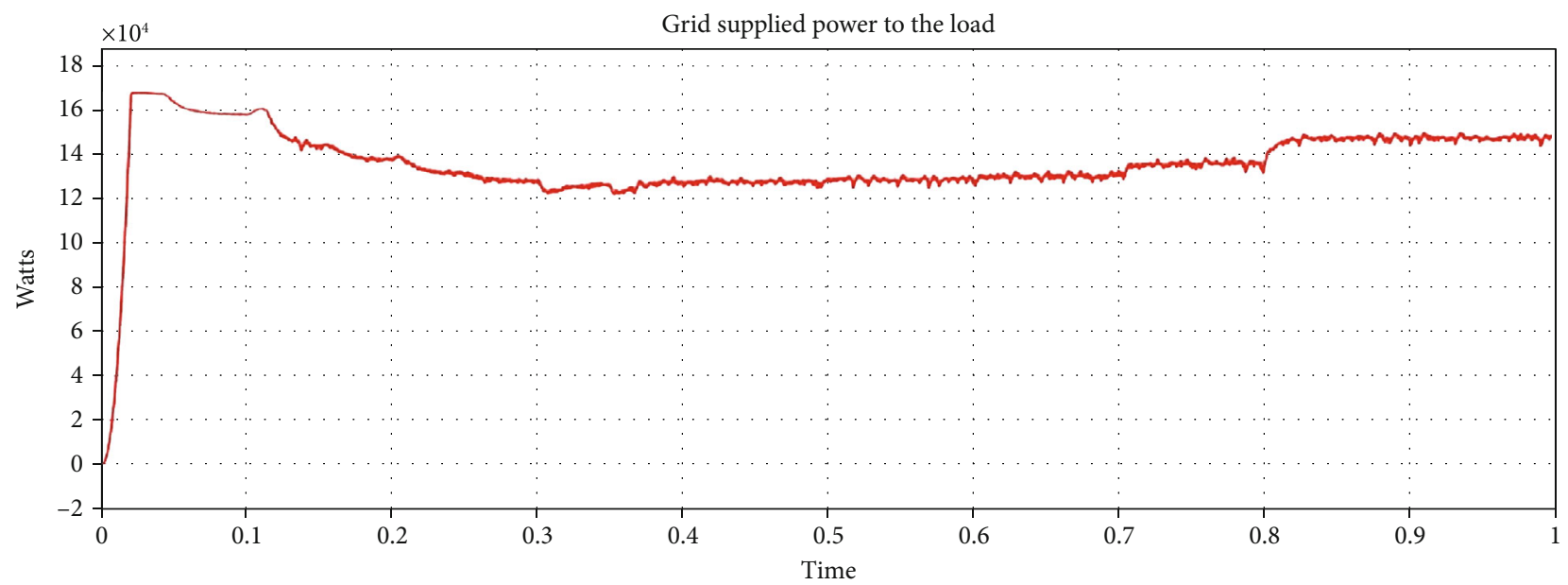

Figure 33: Grid power supplied to the load.

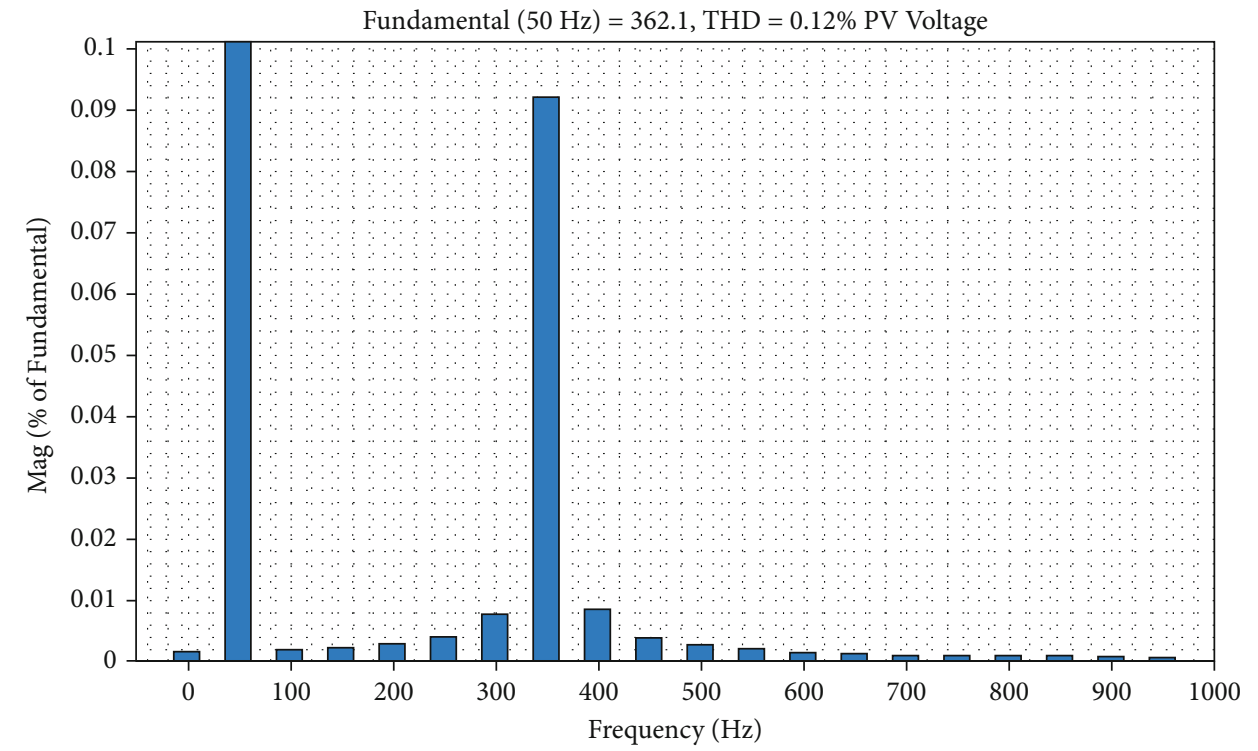

Figure 34: THD values of PV system voltage. 


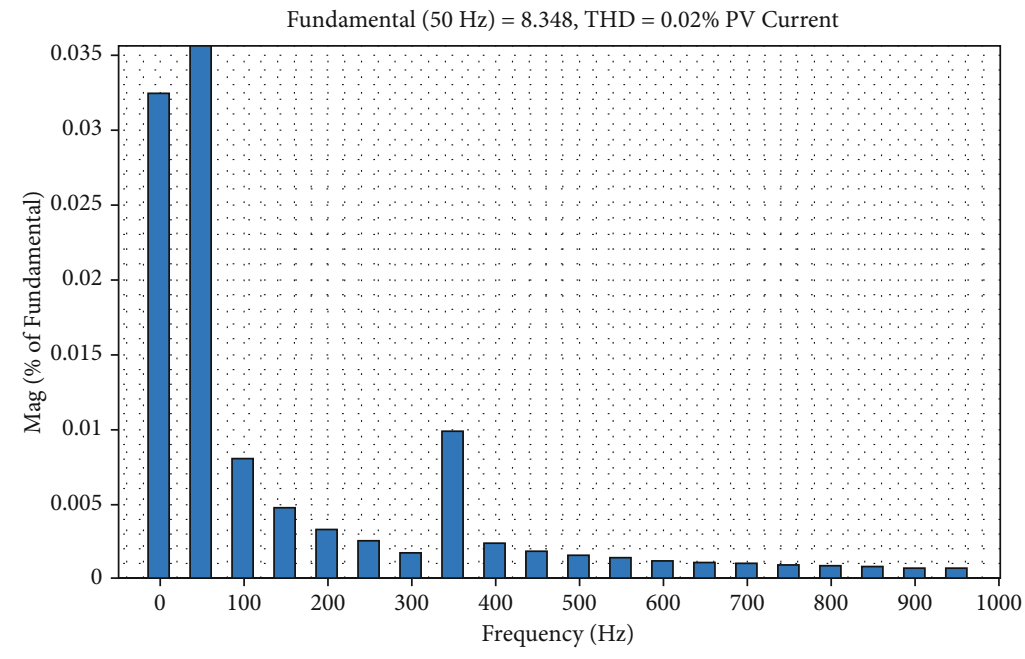

Figure 35: THD values of PV system current.

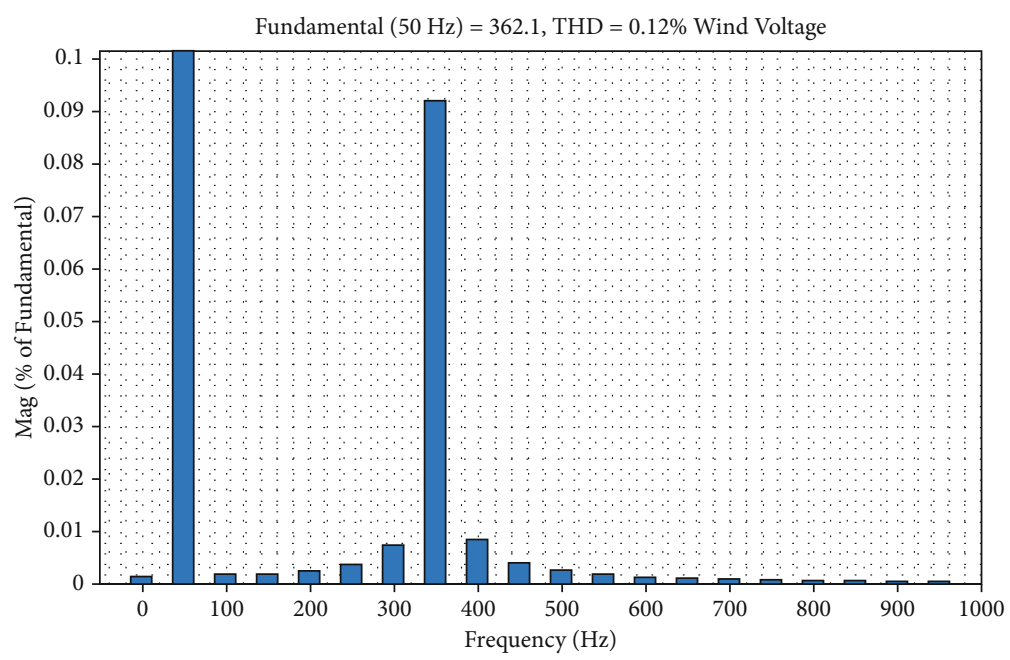

FIGURE 36: THD values of wind voltage.

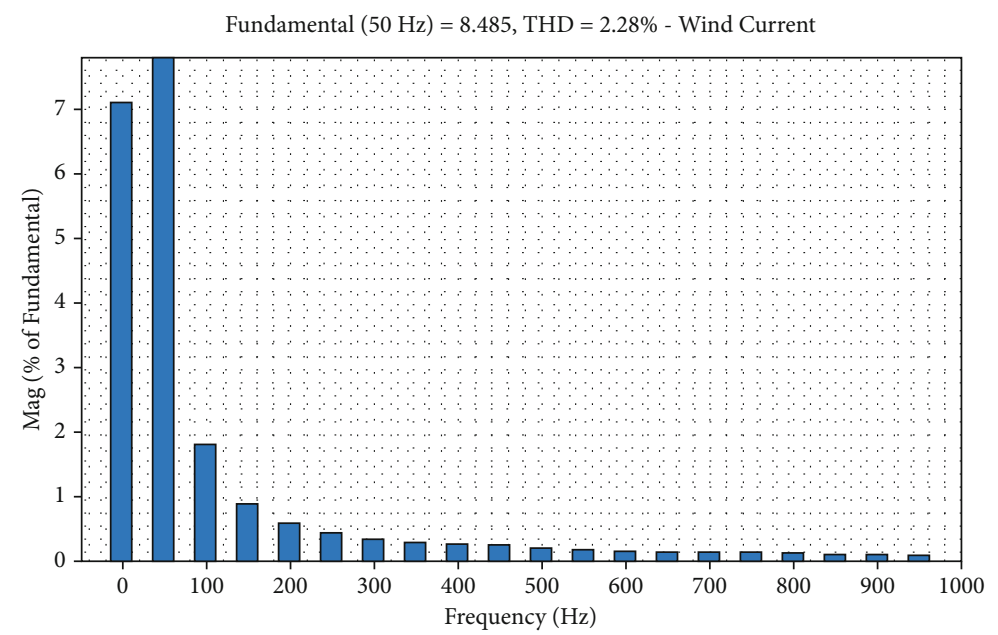

FigURE 37: THD values of wind current. 


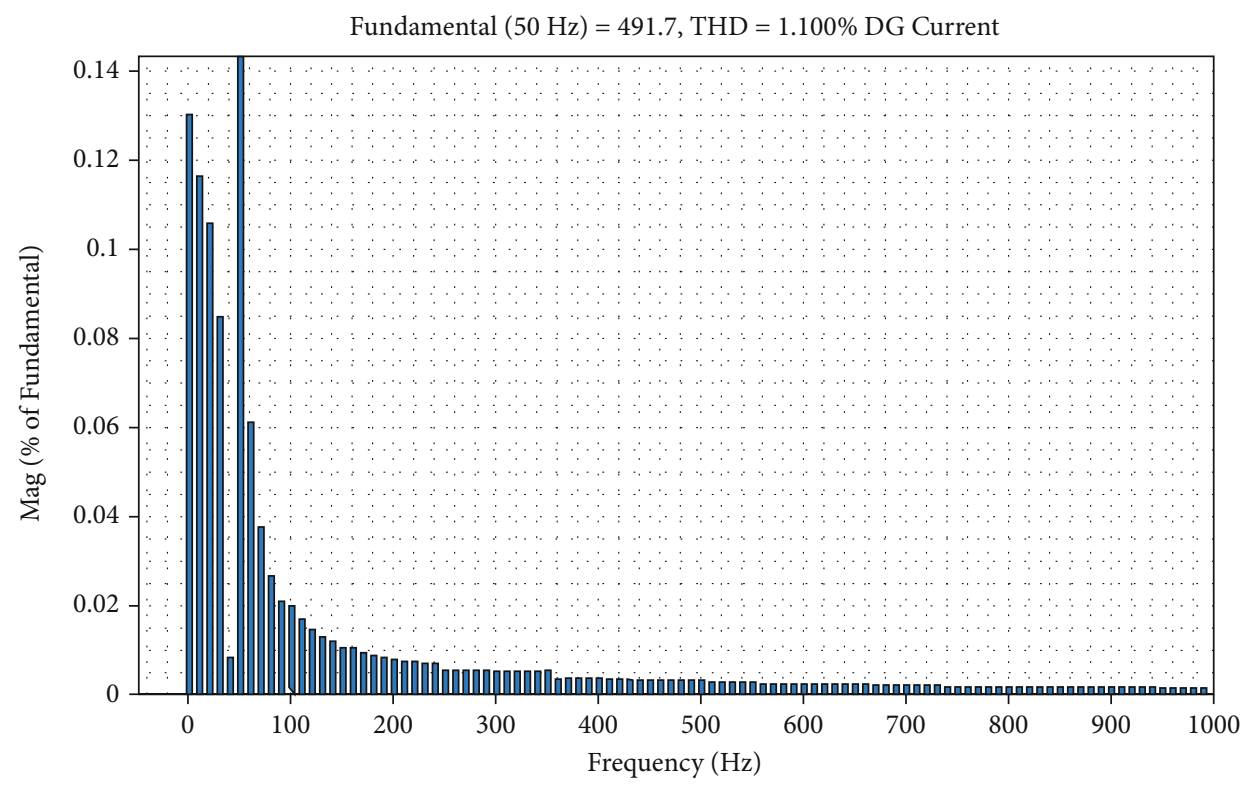

FIgURE 38: THD values of microgrid load current.

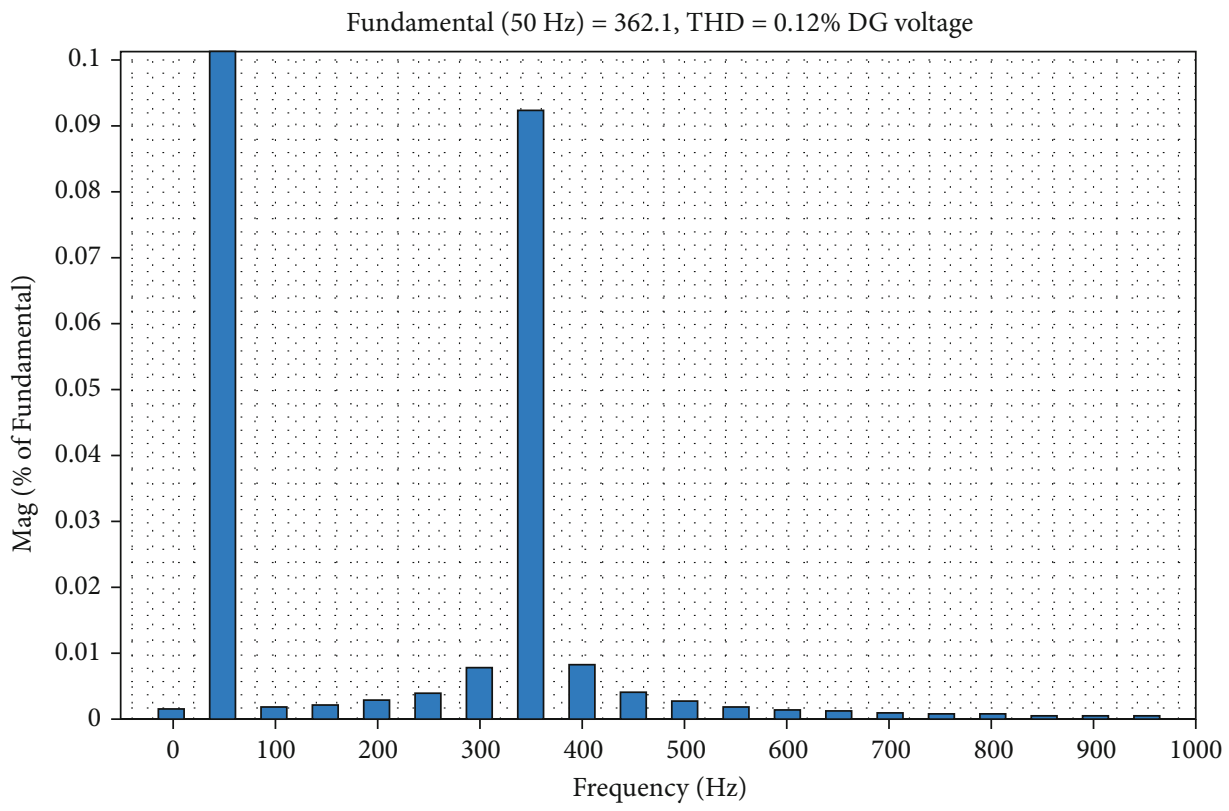

FIGURE 39: THD values of microgrid load voltage.

TABLE 4: Comparative analyses of THD values, grid, wind, and PV.

\begin{tabular}{lcccc}
\hline Profile & $\begin{array}{c}\text { Voltage- } \\
\text { THD } \\
\text { DNN controller }\end{array}$ & $\begin{array}{c}\text { Current- } \\
\text { THD }\end{array}$ & $\begin{array}{c}\text { Voltage- } \\
\text { THD } \\
\text { PI controller }\end{array}$ & $\begin{array}{c}\text { Current- } \\
\text { THD }\end{array}$ \\
\hline Grid & $0.12 \%$ & $0.10 \%$ & $0.17 \%$ & $3.62 \%$ \\
Wind & $0.12 \%$ & $2.28 \%$ & $0.17 \%$ & $29.9 \%$ \\
PV & $0.12 \%$ & $0.02 \%$ & $0.17 \%$ & $0.35 \%$ \\
\hline
\end{tabular}

energy system and hybrid PV/wind. The simulation results are analyzed, and evaluations were performed under different weather conditions to test the proposed controller's effectiveness. The proposed wind energy system and the hybrid $\mathrm{PV} /$ wind were developed and simulated in MATLAB and integrated with a microgrid. The proposed research task has been to develop a simulation model for a smart inverterbased microgrid, which was integrated with a wind energy system and the hybrid PV/wind testing a DNN algorithm in MATLAB environment. We simulated the proposed system in different operating situations and presented the simulation results in this paper. The primary aim of this 
research is to show the THD values of PV, wind, and distributed grid voltage and current profiles, all of which show improvements in power quality when the microgrid is integrated to renewable energy sources. The observed THD values of the proposed system are less than $5 \%$ as per standard (IEEE 1547). The results show the effectiveness of the proposed system; hence, it is recommended for hybrid $\mathrm{PV} /$ wind and grid-connected renewable energy systems.

\section{Data Availability}

The data are all time available.

\section{Conflicts of Interest}

The authors declare that they have no conflicts of interest.

\section{References}

[1] M. Nurunnabi, N. K. Roy, E. Hossain, and H. R. Pota, "Size optimization and sensitivity analysis of hybrid wind/PV micro-grids- a case study for Bangladesh," IEEE Access, vol. 7, pp. 150120-150140, 2019.

[2] R. Singh, R. C. Bansal, A. R. Singh, and R. Naidoo, "Multiobjective optimization of hybrid renewable energy system using reformed electric system cascade analysis for islanding and grid connected modes of operation," IEEE Access, vol. 6, pp. 47332-47354, 2018.

[3] J. Ke and X. Liu, "Empirical analysis of optimal hidden neurons in neural network modeling for stock prediction," in 2008 IEEE Pacific-Asia Workshop on Computational Intelligence and Industrial Application, vol. 2008, pp. 828-832.

[4] M. Xu, L. Wu, H. Liu, and X. Wang, "Multi-objective optimal scheduling strategy for wind power, PV and pumped storage plant in VSC-HVDC grid," Journal of Engineering, vol. 2019, no. 16, p. 3021, 2019.

[5] A. Elgammal and M. El-Naggar, "Energy management in smart grids for the integration of hybrid wind-PV-FC-battery renewable energy resources using multi-objective particle swarm optimisation (MOPSO)," Journal of Engineering, vol. 2018, no. 11, p. 1816, 2018.

[6] X. Li, D. Hui, and X. Lai, "Battery energy storage station (BESS)-based smoothing control of photovoltaic (PV) and wind power generation fluctuations," IEEE Transactions on Sustainable Energy, vol. 4, no. 2, pp. 464-473, 2013.

[7] U. Akram, M. Khalid, and S. Shafiq, "An innovative hybrid wind-solar and battery-supercapacitor microgrid system-development and optimization," IEEE access, vol. 5, pp. 2589725912, 2017.

[8] A. Benali, M. Khiat, T. Allaoui, and M. Denai, "Power quality improvement and low voltage ride through capability in hybrid wind-PV farms grid-connected using dynamic voltage restorer," IEEE Access, vol. 6, pp. 68634-68648, 2018.

[9] Z. Ullah, S. Wang, J. Radosavljević, and J. Lai, “A solution to the optimal power flow problem considering WT and PV generation," IEEE Access, vol. 7, pp. 46763-46772, 2019.

[10] A. Sujil, R. Kumar, and R. C. Bansal, "FCM clustering-ANFISbased PV and wind generation forecasting agent for energy management in a smart microgrid," Journal of Engineering, vol. 2019, no. 18, p. 4857, 2019.
[11] A. A. Z. Diab, H. M. Sultan, I. S. Mohamed, O. N. Kuznetsov, and T. D. Do, "Application of different optimization algorithms for optimal sizing of PV/wind/diesel/battery storage stand-alone hybrid microgrid," IEEE Access, vol. 7, pp. 119223-119245, 2019.

[12] T. Adefarati, R. C. Bansal, and J. J. Justo, “Techno-economic analysis of a PV-wind-battery-diesel standalone power system in a remote area," Journal of Engineering, vol. 2017, no. 13, p. 744, 2017.

[13] N. T. Mbungu, R. C. Bansal, and R. Naidoo, "Smart energy coordination of a hybrid wind/PV with battery storage connected to grid," Journal of Engineering, vol. 2019, no. 18, p. $5113,2019$.

[14] M. Venkateshkumar, "DNN control based MPPT techniques for $40 \mathrm{kWatt}$ wind power Sy, MATLAB Central File Exchange," 2020, https://www.mathworks.com/matlabcentral/ fileexchange/74918-dnn-control-based-mppt-techniques-for40-kwatt-wind-power-sy.

[15] N. Mbungu, R. Naidoo, R. C. Bansal, and M. Bipath, "Optimisation of grid connected hybrid photovoltaic-wind-battery system using model predictive control design," IET Renewable Power Generation, vol. 11, no. 14, pp. 1760-1768, 2017.

[16] N. T. Mbungu, R. M. Naidoo, R. C. Bansal, and V. Vahidinasab, "Overview of the optimal smart energy coordination for microgrid applications," IEEE Access, vol. 7, pp. 163063-163084, 2019.

[17] N. T. Mbungu, R. M. Naidoo, R. C. Bansal, M. W. Siti, and D. H. Tungadio, "An overview of renewable energy resources and grid integration for commercial building applications," Journal of Energy Storage, vol. 29, 2020.

[18] D. H. Tungadio, R. C. Bansal, M. W. Siti, and N. T. Mbungu, "Predictive active power control of two interconnected microgrids," Technology and Economics of Smart Grids and Sustainable Energy, vol. 3, no. 1, 2018.

[19] S. B. Santra, K. Kumar, P. Biswal, and C. K. Panigrahi, "Lyapunov based fast terminal sliding mode $\mathrm{Q}-\mathrm{V}$ control of grid connected hybrid solar PV and wind system," IEEE Access, vol. 6, pp. 39139-39153, 2018.

[20] J. S. Ojo, P. A. Owolawi, and A. M. Atoye, "Designing a green power delivery system for base transceiver stations in southwestern Nigeria," SAIEE Africa Research Journal, vol. 110, no. 1, pp. 19-25, 2019.

[21] S. Messalti, A. G. Harrag, and A. E. Loukriz, "A new neural networks MPPT controller for PV systems," IREC2015 The Sixth International Renewable Energy Congress, 2015.

[22] R. Divyasharon, R. Narmatha Banu, and D. Devaraj, “Artificial neural network based MPPT with CUK converter topology for PV systems under varying climatic conditions," 2019 IEEE International Conference on Intelligent Techniques in Control, Optimization and Signal Processing (INCOS), 2019, pp. 1-6, Tamilnadu, India, 2019.

[23] S. Yushu, Z. Zhenxing, Y. Min, J. Dongqiang, P. Wei, and $\mathrm{X}$. Bin, "Research overview of energy storage in renewable energy power fluctuation mitigation," CSEE Journal of Power and Energy Systems, 2019.

[24] M. Venkateshkumar, "Machine learning based hybrid PV and wind SMATLAB Central File Exchange(2020, https://www .mathworks.com/matlabcentral/fileexchange/75516-machinelearning- based- hybrid-pv-and-wind-pms.

[25] I. Mahendravarman, S. A. Elankurisil, M. Venkateshkumar, A. Ragavendiran, and N. Chin, "Artificial intelligent 
controller-based power quality improvement for microgrid integration of photovoltaic system using new cascade multilevel inverter," Soft Computer, 2020.

[26] R. Indumathi, M. Venkateshkumar, and R. Raghavan, "Integration of D-Statcom based photovoltaic cell power in low voltage power distribution grid," IEEE-International Conference on Advances in Engineering, Science and Management (ICAESM-2012), pp. , 2012460-465, 2012.

[27] C. S. Chin, J. Xiao, A. M. Y. M. Ghias, M. Venkateshkumar, and D. U. Sauer, "Customizable battery power system for marine and offshore applications: trends, configurations, and challenges," IEEE Electrific Mag, vol. 7, no. 4, pp. 46-55, 2019. 